\title{
Face Shield Design against Blast-induced Head Injuries
}

Long Bin Tan ${ }^{1, *}$, Kwong Ming Tse ${ }^{2, *}$, Yuan Hong $\operatorname{Tan}^{1}$, Mohamad Ali Bin Sapingi ${ }^{1}$, Vincent Beng Chye Tan ${ }^{1}$, Heow Pueh Lee ${ }^{1}$

${ }^{1}$ Department of Mechanical Engineering, National University of Singapore ${ }^{2}$ Department of Mechanical Engineering, The University of Melbourne

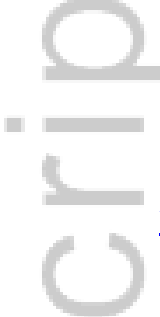

*E-mail: mpetl@nus.edu.sg (Tan, L.B.);

tsekm.research@yahoo.com / kmtse@ unimelb.edu.au (Tse, K.M.)

\begin{abstract}
Blast-induced traumatic brain injury (TBI) has been on the rise in recent years due to the increasing use of improvised explosive devices (IEDs) in conflict zones. Our study investigates the response of a helmeted human head subjected to a blast of 1 atm peak overpressure, for cases with and without a standard polycarbonate (PC) face shield and for face shields comprising of composite PC and aerogel materials and with lateral edge extension. The novel introduction of aerogel into the laminate face shield is explored and its wave-structure interaction mechanics and performance in blast mitigation is analysed. Our numerical results show that the face shield prevented direct exposure of the blast wave to the face and help delays the transmission of the blast to reduce the intracranial pressures (ICPs) at the parietal lobe. However, the blast wave can diffract and enter the midface region at the bottom and side edges of the face shield, resulting in TBI. This suggests that the bottom and sides of the face shield are important regions to focus on to reduce wave ingress. The laminated PC/aerogel/PC face shield yielded higher peak positive and negative ICPs at the

This is the author manuscript accepted for publication and has undergone full peer review but has not been through the copyediting, typesetting, pagination and proofreading process, which may lead to differences between this version and the Version of Record. Please cite this article as doi: $10.1002 / \mathrm{cnm} .2884$
\end{abstract}

This article is protected by copyright. All rights reserved. 
frontal lobe, than the original PC one. For the occipital and temporal brain regions, the laminated face shield performed better than the original. The composite face shield with extended edges reduced ICP at the temporal lobe but increases ICP significantly at the parietal lobe which suggests that a greater coverage may not lead to better mitigating effects.

Words: 248

Keywords: Head Model, Helmet, Aerogel, Coupled-Eulerian-Lagrangian (CEL), FluidStructure-Interaction (FSI), Traumatic Brain Injury (TBI)

\section{Introduction}

The increasing occurrence of blast attacks using improvised explosive devices (IEDs) in modern wars has resulted in high incidence of traumatic brain injury (TBI). A rough estimate by the Joint Theatre Trauma Registry, compiled by the U.S. Army Institute of Surgical Research showed that $22 \%$ of the wounded soldiers suffered injuries relating to TBI [1]. Death and injuries resulting from IEDs accounted for more than $60 \%$ of the U.S. casualties in Afghanistan [2, 3]. The over-pressurised shock wave generated in a blast event can have devastating effect to the human brain.

As such, tremendous efforts have been spent on blast mitigation technology through both experimental and numerical means. There had been numerous studies on the effectiveness of the combat helmets against blast events [4-11] and it was found that the helmet-head gap creates an "underwash" or wave-focusing effect where the blast pressure was amplified $[4,6$, 11, 12]. This has led to the concept of incorporating a face shield onto the combat helmet. Most notably, a study by researchers at Massachusetts Institute of Technology (MIT) 
concluded that combining the helmet with a face shield made of polycarbonate (PC) impeded the direct transmission of the blast waves to the face region, hence lowering intracranial stresses [6]. The study showed sufficient evidence that covering the exposed region of the face would mitigate blast-induced TBI. Another study conducted by Courtney et al. [13] demonstrated that different materials such as PC and laminated glass absorb and reflect the blast wave away to reduce transmission to the face. Murray et al. [14], through small-scale explosive tests, found that thicker shields are able to withstand heavier charges. More recently, Sarvghad-Moghaddam et al. [15] examined the effect of blast directionality on the brain response and the protection capability of the helmet and face shield. They found that the helmet with face shield provided the best protection in the frontal and top blasts. SarvghadMoghaddam et al. [16] also concluded that the implementation of face shield significantly decreases the "underwash" effect in the helmet-head subspace. Despite these, an undesirable effect of the implementation of the face shield onto the combat helmet was observed [16-18]. The blast air that entered into the subspace between the face shield and the face, got trapped (lid-driven cavity effect) and this would impose amplified pressure on the face at the later blast phrase.

In order to improve the effectiveness of face shield in mitigating blast-induced TBI, the present study explored various possible designs of face shields. The present study proposed a layered structure concept with filler material of more superior shock absorbing capability sandwiching between the conventional elastomeric PC layers. Aerogel was chosen to be the filler material, due to its superior properties in shock-absorption [19], thermal insulation, transparency, light weight and micro-porous nature. Moreover, geometrical extension of the 
face shield was studied with the intention of eliminating or reducing the "underwash" and liddriven cavity effects previously reported.

\section{Methods and Materials}

In the present study, various possible designs of face shields mentioned above were explored, as shown in Table 1. Case 1 was the head model with combat helmet but without any face shield. This case was run to compare the head responses with those reported in literature [7, 20-22] for validation purpose. Cases 2, 3 and 4 represented the cases with helmet and face shields. The face shield presented in Case 2 was a conventional PC face shield of an inner diameter of $240 \mathrm{~mm}$, a vertical coverage of $170 \mathrm{~mm}$ and thickness of $3 \mathrm{~mm}$, as shown in Table $1[6,14,23-25]$. The face shield was arced for an angle of 180 degrees from end to end and provides coverage for the front of the face. In Cases 3 and 4, the face shields used were of 3-layered sandwiched structure, with a $1.2 \mathrm{~mm}$ aerogel layer in between two $0.9 \mathrm{~mm}$ PC layers. Furthermore, the face shield in Case 4 was similar to Case 3 but it had an extra extension of $45 \mathrm{~mm}$ from both lateral edges of the face shield (see Table 1).

\subsection{The Finite Element Model}

In order to simulate the fluid-structure interaction (FSI) between the blast air and the helmeted head, the present study adopted a coupled Eulerian-Lagrangian (CEL) approach in Abaqus/Explicit, which allows extreme deformation and blast wave propagation to be modeled effectively. The head, helmet and the face shield were modeled using Lagrangian 
elements while the $330 \mathrm{~mm} \times 330 \mathrm{~mm} \times 330 \mathrm{~mm}$ cubic surrounding air of the blast environment was modeled with Eulerian elements.

The head model features all the essential anatomical components of the human head, comprised of the face, scalp, skull (cortical and trabecular bone), meninges (dura mater, pia mater, tentorium, falx cerebri), cerebrospinal fluid (CSF), cerebrum and cerebellum (Figure 1a). The skull, brain and CSF were meshed using 8-node brick solid elements while 4-node shell elements were used to create the falx, tentorium, pia mater, dura mater, scalp and face.

The helmet model has the geometry of the Kevlar ${ }^{\mathrm{TM}}$ PASGT (Personnel Armor System for Ground Troops) helmet, which is still being used by the defense forces of many countries. The helmet's interior padding system was utilized to cushion the head from shock impact and to reduce the amount of blast wave entering the region between the helmet and the head. The helmet, strap and the backrest were meshed using 8-node brick solid elements while the strips were meshed using 4-node shell elements.

All the material properties of the Langrangian components were provided in Table 2. The bracket was assigned properties of aluminium, while the two outer layers of the face shield were assigned properties of polycarbonate, with the aerogel layer sandwiched between the two layers. The human head was assumed to be linear elastic in the blast simulations. This assumption was consistent with other research [4, 26-28] and was reported to be sufficient to capture the wave propagation characteristics [4, 26-29]. The Kevlar ${ }^{\mathrm{TM}}$ helmet has transverse isotropic properties, which were defined by the material orientations for the elements of the helmet, as shown in Figure 1b. 
The finite element (FE) models of the head and the PASGT helmet in this study had been validated against Nahum et al. [30]'s cadaveric intracranial pressure (ICP) data and used in our ballistic work with Lee and Gong [31]. Readers can refer to the aforementioned paper [31] for modelling, meshing and validation details of the FE models of the head and helmet. The face shield consisted of the visor and the bracket. The dimensions of the face shield are shown in Figure 2. The head/helmet/face shield model contained close to 56,000 Lagrangian elements in total.

Unlike the Lagrangian domain, the elements in the Eulerian domain do not deform but instead allow air to be convected through them. The Eulerian domain contained approximately 1,331,000 hexahedral Eulerian elements $(931,700$ elements if excluding those occupied by the Lagrangian helmet/head assembly) with an average edge length of $2.8 \mathrm{~mm}$ so as to occupy the blast wave environment with high spatial resolution. Results are output at a very high time resolution of $0.001 \mathrm{~ms}$. This mesh size had been verified to be fine enough to capture the peak pressure of the propagating blast wave, and was similar to those used by other researchers studying numerical blast impact analysis on the cranium $[21,22,26,33$, $34]$.

As for the Eulerian domain, it mimicked the surrounding air and was assigned the properties of an ideal gas since real gas behaved approximately like an ideal gas under conditions of low pressure and high temperature. Under 10 atmospheres of pressure or less, the ideal gas law predictions are very close to real amounts and do not generate significant error. The values of the parameters for the ideal gas law used for modelling air in the Eulerian domain were provided in Table 2. 


\section{$\underline{2.2 \text { Load and Boundary conditions }}$}

The head model was assumed to face directly to the blast source and the blast load was applied to the front surface of the Eulerian domain. The other five surfaces were all set as non-reflecting Eulerian boundary surfaces to simulate an infinite domain. They were also applied with the free inflow condition so that material could flow into the Eulerian domain freely. This was because the air that was expelled, needed to return during the negative pressure phase of the blast wind that will draw air back to the blast source. If the air did not return, it would produce a higher negative air pressure ambience which is not realistic. The boundary conditions of the surfaces were illustrated in Figure 3a.

The blast wave might also displace the head model since the body below the neck was not represented. To prevent excessive head motions from occurring and to provide a realistic compliance for the blast-wave impact to the head, the displacement constraints were applied at the base of the neck region instead of directly at the base of the skull.

A typical blast wave profile usually consists of the positive pressure wave and the subsequent wind that follows right after it [38]. The waves may wrap around or reflect from physical objects to cause pressure amplifications [7, 22]. The Friedlander waveform was used to describe the pressure of the blast wave with respect to time and its main characteristics is the peak overpressure depicted by the highest point which is attained very quickly and then decreases exponentially to below atmospheric pressure, until a maximum negative pressure is reached, before rising back up to ambient $[7,22,39,40]$. 
A $1.0 \mathrm{~ms}$ blast profile with a peak overpressure of 1 atm and a negative pressure phase initiating from $0.3 \mathrm{~ms}$ was applied to the front surface of the Eulerian domain (see Figure $3 \mathrm{~b}$ ), to produce the planar blast, which was similar to the pressure wave experienced from a $28.4 \mathrm{~g}$ TNT charge explosive at a standoff distance of $0.81 \mathrm{~m}[41,42]$. Similar to the blast overpressure magnitudes of other studies [7, 20, 22, 23, 43], this seemingly low blast overpressure of $1 \mathrm{~atm}$ was particularly chosen in our study since approximately $50 \%$ of the Tympanic Membrane (TM) rupture, which is the most common form of primary blast injury, will occur at 1.02 atm $[44,45]$. It should be noted that a blast wave of 5 atm overpressure will cause fatal damage and disintegration of body parts.

\section{$\underline{2.3 \text { Contact and Fluid-Structure Interaction }}$}

The Lagrange-Lagrange contact interactions, with kinematic coupling, were utilized between all Lagrangian components such as those between the scalp and the interior helmet paddings, and between the helmet paddings and the Kevlar helmet shell, where contacting surfaces had their penetrations resisted by linear spring forces with their values proportional to the depth of penetration as provided by Hertzian contact laws. As a result, these forces reached an equilibrium position in which there was no penetration and the transmitted contact stresses between two bodies were then calculated.

Interaction between the Lagrangian helmeted head and the Eulerian ambient air were simulated with the Coupled Eulerian-Lagrangian (CEL) analysis code in Abaqus ${ }^{\mathrm{TM}}$ that was formulated using the enhanced immersed boundary method. The Abaqus's Eulerian Volume Fraction (EVF) tool was used to separate the space occupied by the Lagrangian material in the Eulerian domain. The Lagrangian part located inside the Eulerian part was applied with 
"no-flow" boundary condition by default so that the convective flow during the analysis was able to "see" the Lagrangian surfaces and was prevented from occupying the same space taken up by the Lagrangian components. The resulting interactions between the Lagrangian and Eulerian components were then calculated and tracked by a contact algorithm. As the Lagrangian helmeted-head was placed in the Eulerian ambient air mesh, it was required to ensure that no air properties were occupying the overlapped regions, by defining them as "void" regions. Similar techniques had also been used by Grujicic et al. [34] and Tan et al. [7] in their blast simulations.

The face shield assembly was mounted onto the helmet by applying tie constraints so that no air can slip through the gaps between the face shield and the bracket and that the components do not separate as the blast wave passed through.

\subsection{Analysis Landmarks}

For the blast analysis, four anatomical landmarks were taken at the skull and cerebrum respectively, to study the head and brain responses. The ICPs were evaluated at the frontal, parietal, occipital and temporal lobes of the cerebrum (see Figure 4a and 4b). The von Mises stresses at the skull were also evaluated at the four regions and are namely the frontal, top, rear and side points (see Figure $4 \mathrm{c}$ and $4 \mathrm{~d}$ ). To study the effectiveness of the different configurations of the face shield in reducing the amount of pressure wave ingress from the bottom edge and in air pressure retention, air pressures at the vital features of the face, such as the eye, nose and mouth were also extracted (see Figure 4e). Moreover, von Mises stresses and deflections of the face shield were also analysed over the entire blast sequence, to ensure that they did not reach the yield or failure threshold and shatter. 


\section{Results and Discussion}

\section{$\underline{\text { 3.1 Comparison of results for cases with and without face shield (Case } 1 \& \text { Case 2) }}$}

Figures $5 \mathrm{a}$ and $5 \mathrm{~b}$ show both the mid-sagittal and mid-axial views of the blast wave impacting the helmeted-head model, for cases with and without face shield protection (Case 1 and Case 2), respectively. When the head was protected by the PAGST helmet alone (Case 1), the blast wave impacted the face and helmet at around $0.2 \mathrm{~ms}$. The helmet helped to deflect the wave and both the head and helmet did not experience much displacement during the blast sequence. The blast wave was seen to accumulate at the region just below the chin at around $0.4 \mathrm{~ms}$. The wave then wrapped around the head to give a secondary impact at the rear of the neck and head (occipital lobe) between 0.7 and $0.85 \mathrm{~ms}$. The blast front took around $0.9 \mathrm{~ms}$ to pass by the head model and at $1.0 \mathrm{~ms}$, the negative phase of blast (blast wind) set in which caused the wave to travel back to the front. For the case with face shield (Case 2), the blast wave struck the face shield at around $0.1 \mathrm{~ms}$, and between 0.2 to $0.3 \mathrm{~ms}$ the face shield prevented the direct exposure of the blast wave to the face. However, the blast wave diffracted at the bottom edge of the face shield and entered the region between the face and the face shield.

The axial views of the blast pressure contours for the two cases were included in Figure 5 as these provide a better perspective on how the blast wave entered from the sides of the helmet since this could not be shown by the sagittal views. It can be observed that the face shield diffracted the blast away and delayed the wave from entering the ear-cover region of the helmet compared to the case without face shield. In addition, the wave was seen to enter the gap between the helmet and head and converged at the occipital region of the head at 
around $0.85 \mathrm{~ms}$ and $0.95 \mathrm{~ms}$, for the cases without and with face shield, respectively. The contours provided evidence that a face shield could also potentially delay the secondary blast wave impact at the rear of the head. As time progressed, the negative pressure phase of the blast caused accumulated high air pressure between the face shield and the face at around 1.4 ms into the blast sequence (see Figure 5b). This observation was identical to that of Sarvghad-Moghaddam et al. [16] and this may lead to facial injuries.

Table 3 shows the peak ICPs at the frontal and parietal lobes for cases with and without face shield. The peak ICPs at the parietal lobes generally decreased with the use of the face shield. The reductions of peak positive and negative ICPs at the parietal lobe were about $22 \%$ and $6 \%$ respectively, with greater attenuation for positive pressure. However, for frontal lobe, an increase of $16 \%$ in positive ICP was observed with the use of the face shield, while having about $27 \%$ reduction in the negative peak brain pressure. The blast modeling of $0.1 \mathrm{MPa}(1$ atm) peak overpressure impact on a head model was also reported by Grujicic et al. [34] who obtained ICP values ranging from -80 to $80 \mathrm{kPa}$. Zhang et al. [20] reported peak ICPs of 600 $\mathrm{kPa}$ from 0.27 MPa (2.7 atm) peak overpressure TNT blast for the helmeted case. Simmonds et al. [43] reported ICPs of around $350 \mathrm{kPa}$ for a helmet/head model experiencing approximately 2 atm peak pressure blast wave impinging on the face of the head. Lockhart and Philip [23] also investigated blast wave interaction on the head for cases with and without helmet protection. For the peak incident overpressure of around $1.2 \mathrm{~atm}$, a pressure field at the rear of the head of around $3.4 \mathrm{~atm}$ was created. The ICPs obtained were about 600 $\mathrm{kPa}$. Tan et al. [22] also reported peak ICPs of around $120 \mathrm{kPa}$ for numerical blast impacts of a biological head model protected by the Advanced Combat Helmet $(\mathrm{ACH})$ with different foam paddings. The Friedlander blast profile used was a peak overpressure of 1atm with a 
positive pulse duration of $1.2 \mathrm{~ms}$. The peak ICPs obtained from our head model were slightly higher than those reported by Tan et al. [22] due to their inclusion of foam paddings within the helmets while the current model used the strap suspension system. Extra padding had been reported to mitigate the blast wave effects on the head [46, 47]. Even though the head and helmet models may be different, comparison of our results with the published values showed that similar magnitudes of ICPs were obtained, and hence ascertain the appropriate modeling methodology used.

For our helmeted case without face shield, the skull stresses at the front and top points were 4.58 $\mathrm{MPa}$ and $2.85 \mathrm{MPa}$ respectively. These were about the same magnitude as observed by Tan et al. [22] who obtained a peak von Mises skull stress of about $8 \mathrm{MPa}$ for a $1 \mathrm{~atm}$ peak overpressure blast to a helmeted-head model. Slight differences in geometry of the components of the head model, configuration of the helmet and its interior pad system, the use of different analysis codes and material properties would result in slightly different ICPs and skull stresses. As our results for the model without face shield were in the same order as those published, the model was validated in terms of accuracy in peak ICP and skull stress predictions. The same head model was also used in the analysis involving impact of complex blast waves on the human head [7].

The effect of the face shield was seen in Figure 6 to prevent the initial blast wave impact on the face and forehead, and hence eliminating the initial peak in ICP at the frontal lobe. However, the face shield was likely to cause a higher peak ICP to the frontal lobe at a later time due to retained high pressure air. The face shield also helped to lower the ICP at the parietal (top-rear) lobe. An injury index for ICP was suggested by Ward et al. [48] to assess brain injury severity and the occurrence of cerebral contusion. This index was based on 
combined analytical and live animal experimental investigation of brain injury. According to this ICP tolerance criterion, serious brain injury occurs when the peak ICP exceeds $235 \mathrm{kPa}$, while minor or no brain injuries would occur when the resulting ICP is below $173 \mathrm{kPa}$. For both cases, the ICPs were generally lower than $235 \mathrm{kPa}$, which was the referenced threshold for serious brain injury $[48,49]$. The criterion was also used by various researchers $[7,28]$ for head blast injury assessment. It could be seen evidently from Figure 6 that with the face shield, the initial ICPs were lower than those obtained for the case without face shield. However, at a later time, the case with the face shield shows an extended duration of high ICP beyond $1.6 \mathrm{~ms}$, while the case without the face shield already shows gradual dissipation and subsiding of the ICP.

Figure $7 \mathrm{a}$ and $7 \mathrm{~b}$ shows the comparison of peak ICPs and peak von Mises skull stresses at various anatomical locations for the 4 different cases. Although the peak ICPs from the case without face shield was lower than those with face shields, the authors believe that as long as the ICPs do not exceed the threshold values, face shields would still be useful against secondary blast injuries accruing from possible flying debris and shrapnels.

3.2 Comparison of results between PC and PC/aerogel/PC composite face shields (Case $2 \&$ $\underline{\text { Case 3) }}$

The same blast scenario was performed again, with the PC visor modified to the three layers, PC/Aerogel/PC, structure. The time-history plots of the ICPs (as shown in Figure 8a) show that the evolution of the profile was identical until around $0.9 \mathrm{~ms}$ where the blast front had passed the head and the negative phase of the blast had set in to draw the pressure back. Table 4 presents the results of both the peak ICPs and skull stresses for the two cases. The PC 
face shield (no aerogel) delayed the occurrence of the high ICP as compared to the case without face shield, but it eventually caused a higher peak ICP to be registered at the frontal lobe at a later time of about $1.7 \mathrm{~ms}$. The laminated face shield performed worse than the original PC one, particularly for negative ICP. This was likely due to the weaker overall stiffness of the face shield that also yielded a higher dynamic flexure during the blast sequence than the original face shield. The greater deflection was believed to induce a greater drag by the blast wave on the face shield and helmet, and also had an effect on the air near the face, such as to yield more detrimental results on the frontal lobe. The results at the parietal lobe show that both face shields yielded very close peak positive ICP values while the negative values indicated that the sandwiched structured face shield performed better. This was in contrast to the ICP results for frontal lobe where higher negative ICPs were obtained from the sandwiched structured face shield. A plausible reason for the brain response was that the less stiff composite face shield tended to vibrate more and for a longer duration during excitation which might have an adverse effect on the frontal lobe, but its application reduced ICPs at the parietal, occipital and temporal lobe regions. Figures $8 \mathrm{a}$ and 8b also show greater fluctuation of ICPs for the case with laminated face shield, as observed through the time-history plots. The ICPs tended to gradually reduce to much lower values after $2 \mathrm{~ms}$. The study shows that stiffer face shields could likely perform better than compliant ones against blast impact. Comparison of the results against the conventional PC face shield (Case 2) showed that the laminated face shield (Case 3) yielded generally lower ICPs at various locations of the brain (except for frontal lobe). Although this design of lamination in the face shield would generally increase peak skull stresses, these stresses were considered non-injurious as compared to the skull fracture threshold of around $75 \mathrm{MPa}$ 
reported by Wood [50]. This shows that the laminated face shield may be a viable design for blast-induced TBI if proper padding or interior helmet cushions could be implemented so as to reduce wave ingress to the gap spaces between the helmet and the top of the head.

$\underline{3.3 \text { Comparison of results for the composite face shield with and without } 45 \mathrm{~mm} \text { edge }}$ extension (Case $3 \&$ Case 4)

The axial views as observed from the top of the head model are used to analyse the wave propagation around the head. The elevation at which the axial view was obtained just below the front helmet rim where the effect of different face shield designs is being investigated while the helmet and interior cushions remain unchanged. The axial views also allow assessment if greater edge extensions of the face shield will reduce blast wave entry to the facial and helmet/head gap regions, and prevent blast wave confluence at the rear of the head. When the laminated face shield with no extension was equipped (Case 3), the blast waves began to strike the front of the face shield just before $0.1 \mathrm{~ms}$ (Figure 9a). There was little or no exposure to the blast wave at the front of the face from $0.2 \mathrm{~ms}$ to $0.3 \mathrm{~ms}$ and this was due to the face shield deflecting the blast wave away from the front of the head. The high pressure air appearing at $0.4 \mathrm{~ms}$ at the front of the face was attributed to the propagation of blast wave under the face shield and diffracting upwards onto the face (Figure 9a). However, by comparing the air pressure contours, this diffracted wave behind the face shield was of a lower pressure than those outside the face shield and this showed that the face shield helped to reduce the pressure of the blast wave to the face. This blast wave then propagated inside the face shield before meeting the blast wave outside the face shield at the back of the head at around $0.65 \mathrm{~ms}$ (Figure 9a). For Case 4 (laminated face shield with $45 \mathrm{~mm}$ extension), the 
blast wave was observed to reach the side edges of the face shields at different times for different edge extension lengths (Figure 9b). For the face shield without extension, the blast wave reached the side edges at $0.4 \mathrm{~ms}$ while for the $45 \mathrm{~mm}$ face shield extension, it took 0.5 ms. The extended face shield edge effectively reduced high pressure wave at the temporal (side) regions of the head as the outer and inner waves (see Figure 9b) only managed to merge at the further rear of the head. It was noted that some high pressure air was generated in front of the face shield, at around $0.5 \mathrm{~ms}$ into the blast sequence, as the face shield flexed back due to elastic recovery and wave ingress from underneath the face shield. The blast waves converged at the back of the head at around $0.8 \mathrm{~ms}$ to $0.9 \mathrm{~ms}$. At around $1.0 \mathrm{~ms}$, the negative pressure phase induced the blast wave to start travelling back to the front. The curvature of the face shield accumulated high pressure air in front of the face at $1.9 \mathrm{~ms}$. Thereafter, the blast wave progressively dissipated and there were no more regions of high pressure.

In regards to responses of the intracranial content, it can be seen from Figure 10 that Case 4 (with the $45 \mathrm{~mm}$ face shield extension) yielded much higher maximum ICP when compared to the un-extended face shield case (Case 3). The higher parietal ICP might be due to the greater lateral coverage that prevented high pressure wave between the head and the helmet from escaping, after wave ingress from the ear-cover regions. Hence, to improve the current design for head protection, higher pressure air must be prevented from entering the gap spaces between the head/face and the helmet or the face shield. Further, the difference in ICP might also be due to the way different face shield extensions deflected the shock wave and dissipated the energy. The length of the face shield extension might affect its flexural stiffness to cause complications in air pressure fields near to the face and sides of the head 
during blast wave impact. The longer face shield might also cause a greater accumulation and retention of high pressure air at the front of the face or around the head than one with a shorter extension especially during the negative pressure phase of the blast. However, if the face shield coverage was not extensive, there would be less head protection against direct blast wave impact and wave ingress.

Comparison of the peak ICPs, as demonstrated in Figure 7a and Table 4, shows that the lateral extended face shield (Case 4) generally helps to lower ICPs at the frontal and temporal lobes, compared to the un-extended one (Case 3), but increased ICPs at the parietal and occipital lobes. From Figure 7b, the face shield with no extension (Case 3) gave higher stresses at the sides and top regions on the skull than the face shield with $45 \mathrm{~mm}$ extension yielded. Results showed that the lateral edge extended face shield helps reduce wave impact to the sides of the head. The higher skull stresses at the front and rear regions were due to the wave convergence at the rear of the head and the later accumulation of high pressure air between the face and the face shield. The general magnitude of skull stresses did not vary much among the cases and that the maximum values were far from the thresholds for skull fracture [50]. The ICPs and skull stresses collectively showed that high skull stresses were not necessarily required to induce relatively high ICP to cause brain injuries. This was particularly the case for blunt impact where the skull may be intact but TBI would have already occurred. A general trend observed for all helmeted cases, except the case for lateral edge extended face shield, was that the top of the head was the area best protected, with the lowest stresses, while the top and sides of the head had higher stresses and hence were the least well protected. 


\section{$\underline{3.4 \text { Air Pressure near the Face }}$}

The air pressure near the face (see Figure 11) was obtained for the head model with and without face shield to provide another quantitative indicator of the dispersion effect of the blast wave as it propagated under the face shield. The results showed that the face shield significantly reduced air pressures at the eye, nose and mouth. In particular, the air pressure near the eyes $(>0.16 \mathrm{MPa})$ was double that obtained near the nose and mouth. This indicated that eye protection from the use of goggles will be very crucial if a face shield is not available as a standard army issue. The reduction in air pressure was especially significant between 0.2 $\mathrm{ms}$ to $0.4 \mathrm{~ms}$ into the blast when the blast front was diffracted by the face shield. For the head model with the face shield, the maximum pressure occurred around $1.9 \mathrm{~ms}$ which was the period when the blast wave got accumulated in the front of the face. It was noted that, for this phenomenon, the higher air pressures were located at the nose and mouth, while the eyes experienced slightly lower pressures of around $0.05 \mathrm{MPa}$. We also noted that the exact geometry of the facial regions plays an important part in the resulting stagnation pressures obtained, and that different people may have slightly different facial contours.

For face shield design, besides frontal impact by the blast wave, we noted that the wave confluence at the rear $\left(2^{\text {nd }}\right.$ impact $)$ of the head and drag of the wave along the sides of the head could have provided "multiple" wave impacts to the head to result in higher skull stresses and ICP. Therefore, air pressures obtained from just the face might not be completely indicative of the face shield performance. This revelation could help engineers design better tests whereby data of blast air pressures particularly at the sides and rear of the head, should also be measured and taken into account for face shield design. 
The resulting ICP might also depend on factors such as the nasal, oral and ear cavities. Wave ingress into the cavities may amplify or reduce the resulting ICP to cause additional differences in values obtained between simulation and physical test. Work is ongoing to include the modeling of these cavities in our next generation head models for the studying of blast effects, so as to take into account the wave ingress into such cavities.

\subsection{Integrity of face shield and possibility of shattering and inflicting facial injuries}

During the blast sequence, there is a chance that the maximum stress experienced by the individual layer of face shield may exceed the failure stress of the material. If this is the case, the face shield will shatter and the fragments may possibly hit the face, causing penetrating head injuries. The maximum yield stresses for PC and aerogel are around $62 \mathrm{MPa}$ [51] and 0.6 MPa respectively $[52,53]$. Figure 12 shows that the maximum attained stresses were 6.2 MPa for PC and 0.15 MPa for aerogel, which are well within the threshold strengths. Further tests can be carried out with a higher peak overpressure blast to simulate the effects of the face shield shattering.

\section{$\underline{\text { 3.6 Limitations }}$}

The main limitation of our work is that the head model was modelled as elastic properties. However, it is considered justifiable as these were found to be sufficient to capture the wave propagation characteristics [4, 26-29]. Viscoelastic properties of the brain were reported to have very long relaxation times $(>0.012 \mathrm{~s})$ to attain their long-term modulus, and as such, within the time-frame of our analysis $(\sim 3 \mathrm{~ms})$ the properties would be similar to those of linear elasticity. This confirmation was also verified by Petr et al. [54] where it was 
concluded that the least important source of error for blast effects in the human brain was the assumption of linear constitutive equation of the brain. Furthermore, unlike SarvghadMoghaddam et al. [15] and Zhang et al. [20] who used much higher blast overpressures of up to $520 \mathrm{kPa}$ and $660 \mathrm{kPa}$ respectively for their studies, our blast overpressure was $101 \mathrm{kPa}$ whereby the induced brain response would likely fall within the elastic portion of the material curve. This assumption may be limitedly realistic but suffice for the primary purpose of comparing the performance between different face shields.

Moreover, our study only related the face shields' performance against a frontal blast. As such, there was paucity of information to conclude on the overall performance of the face shields for other blast directions at this moment. However, most of the literature focusing on frontal blast as it is the primary mitigation direction. In this regard, this blast direction was investigated to analyse the performance of various face shield designs in the main intended mitigation direction rather than other directions. The results from this study would allow researchers to compare values across literature to form a conclusion on the effectiveness of the designs.

\section{Conclusion}

The coupled Eulerian-Lagrangian (CEL) approach was used to simulate the frontal blast impacting on the helmeted head for a $3 \mathrm{~ms}$ duration, and to determine the effectiveness of different face shield designs in mitigating the effect of a blast wave. It was found that the face shield prevented the direct exposure of the blast wave to the face and help delays the transmission of the blast by eliminating the initial peak in ICP at the frontal lobe. However, the blast wave could diffract at the bottom edge of the face shield and enter the region near 
the face. A higher peak ICP at the frontal lobe might occur at a later time due to retained high pressure air in the face shield-face subspace.

Our results showed that the peak ICPs at the parietal lobe generally decreased with the use of the helmet and face shield. The reduction of peak positive and negative ICPs at the parietal lobe were about $22 \%$ and $6 \%$ respectively, with greater attenuation for positive pressure. However, for frontal lobe, an increase of $16 \%$ in positive ICP was observed with the use of the face shield, while having about $27 \%$ reduction in the negative peak brain pressure. The face shield with PC and aerogel layers reduced ICPs at the parietal, occipital and temporal lobe regions. However, it aggravated ICP at the frontal lobe and this was likely due to the weaker overall stiffness of the face shield that yielded a higher dynamic flexure and vibrated more and for a longer duration during the blast sequence. The study showed that stiffer face shields could likely perform better like compliant ones against blast impact.

Extending the lateral edges of the face shield lowered the ICPs at the frontal and temporal lobes but increased ICP significantly at the parietal lobe. The results suggested that a greater coverage of the face shield might not lead to better mitigating effects due to obstruction of high pressure wave from escaping. For von Mises stresses on the scalp, a general trend observed for the helmeted cases was that the top of the head was the most protected, with the lowest stresses, while the sides of the head yielded the greatest stress and hence was the worst protected.

For the head model with and without face shield, the 1atm peak overpressure blast is found to generate ICPs not exceeding $235 \mathrm{kPa}$ which is the threshold for serious head injuries. The face shield is found to significantly reduce air pressures at the eye, nose and mouth. In particular, the air pressure near the eyes $(>0.16 \mathrm{MPa})$ is double that obtained near 
the nose and mouth. This indicates that eye protection from the use of goggles will be very crucial if a face shield is not available as a standard army issue. Although the ICPs from the case without face shield is lower than those with face shields, as long as the ICPs do not exceed the threshold values, face shields will still be useful against secondary blast injuries accruing from possible flying debris and shrapnels.

\section{Conflict of Interest}

The authors declares that there is no conflict of interest in this work.

This article is protected by copyright. All rights reserved. 


\section{References}

[1] Okie S. Traumatic brain injury in the war zone. The New England journal of medicine. 2005;352:2043-7.

[2] Top general expects IED problem to rise in Afghanistan. . 2012. Retrieved from: http://security.blogs.cnn.com/2012/12/13/top-general-expects-ied-problem-to-rise-inafghanistan/. (Accessed on 25th June 2015).

[3] Tomlinson S. Incredible footage shows ISIS suicide bomber's car explode in MID-AIR after vehicle is blasted skywards seconds before driver's IEDs detonate. 14th April 2015 ed: MailOnline; 2015.

[4] Moss WC, King MJ, Blackman EG. Skull flexure from blast waves: a mechanism for brain injury with implications for helmet design. Phys Rev Lett. 2009;103:108702.

[5] Ganpule S, Gu L, Chandra N. Modeling shock response of helmeted head using fluid structure interaction. 16th US National Congress of Theoretical and Applied Mechanics. Pennsylvania, USA2010. p. 1-3.

[6] Nyein MK, Jason AM, Yu L, Pita CM, Joannopoulos JD, Moore DF, et al. In silico investigation of intracranial blast mitigation with relevance to military traumatic brain injury. Proceedings of the National Academy of Sciences. 2010.

[7] Tan LB, Chew FS, Tse KM, Tan VBC, Lee HP. Impact of complex blast waves on the human head - a computational study. International Journal for Numerical Methods in Biomedical Engineering. 2014;30:1476-505.

[8] Jenson D, Unnikrishnan VU. Energy dissipation of nanocomposite based helmets for blast-induced traumatic brain injury mitigation. Composite Structures. 2015;121:211-6.

[9] Grujicic M, Bell WC, Pandurangan B, Glomski PS. Fluid/structure interaction computational investigation of blast-wave mitigation efficacy of the advanced combat helmet. J of Materi Eng and Perform. 2011;20:877-93.

[10] Sharma S, Zhang L. Prediction of intracranial responses from blast induced neurotrauma using a validated finite element model of human head. Ohio State University Injury Biomechanics Symposium. Ohio, US2011.

[11] Sarvghad-Moghaddam H, Karami G, Ziejewski M. Examination of the blast-induced underwash effect on a helmeted head and the response of the brain. The 17th US National Congress on Theoretical and Applied Mechanics. Michigan State University2014.

[12] Sarvghad-Moghaddam H, Rezaei A, Ziejewski M, Karami G. CFD modeling of the underwash effect of military helmets as a possible mechanism for blast-induced traumatic brain injury. Computer Methods in Biomechanics and Biomedical Engineering. 2017;20:1626.

[13] Courtney ED, Courtney AC, Courtney MW. Blast wave transmission through transparent armour materials. Journal of Battlefield Technology. 2012;15:19-22.

[14] Murray C, Jenkins P, Miller S. Protective equipment for small-scale laboratory explosive hazards. Part 2. Shielding materials, eye and face protection. Journal of Chemical Health and Safety. 2015;22:18-33.

[15] Sarvghad-Moghaddam H, Jazi MS, Rezaei A, Karami G, Ziejewski M. Examination of the protective roles of helmet/faceshield and directionality for human head under blast waves. Computer Methods in Biomechanics and Biomedical Engineering. 2015;18:1846-55. 
[16] Sarvghad-Moghaddam H, Rezaei A, Ziejewski M, Karami G. Evaluation of brain tissue responses because of the underwash overpressure of helmet and faceshield under blast loading. International Journal for Numerical Methods in Biomedical Engineering. 2016:e02782-n/a.

[17] Jason AM. Facial Protective devices for blast-induced traumatic brain injury mitigation. Cambridge: Massachusetts Institute of Technology; 2010.

[18] Kulkarni SG, Gao XL, Horner SE, Zheng JQ, David NV. Ballistic helmets - Their design, materials, and performance against traumatic brain injury. Composite Structures. 2013;101:313-31.

[19] The Frontier. Aerogels: Their History, Structure, and Applications. 2011. Retrieved from: http://geobeck.tripod.com/frontier/aerogels.html. (Accessed on 25th June 2015). [20] Zhang L, Makwana R, Sharma S. Comparison of the head response in blast insult with and without combat helmet. Wayne State University, Report for USADOD, W81XWH-08-10678 (LYZ); 2011. p. 1-18.

[21] Grujicic M, Arakere G, He T. Material-modeling and structural-mechanics aspects of the traumatic brain injury problem. Multidiscipline Modeling in Materials and Structures. 2010;6:335-63.

[22] Tan LB, Lee HP, Tan VBC. Performance evaluation and design improvement of interior cushioning system of ballistic helmets. Singapore: National University of Singapore, Report for The DSO National Laboratories, Defence Medical and Environmental Research Institute (DMERI); 2012.

[23] Lockhart PA. Primary Blast Injury of the Head: Numerical Prediction and Evaluation of Protection. Waterloo: University of Waterloo; 2010.

[24] Miller S, Jenkins P, Murray C. Explosive testing of personal protective equipment in a laboratory accident scenario, Explosives Engineering. Journal of the Institute of Explosives Engineers, Explosives Engineering. 2014.

[25] IM22-L6FM, IM22-L6F models, polycarbonate face shields against explosive blast to. [26] Ganpule S, Gu L, Alai A, Chandra N. Role of helmet in the mechanics of shock wave propagation under blast loading conditions. Comput Methods Biomech Biomed Engin. 2012;15:1233-44.

[27] Moore DF, Jerusalem A, Nyein M, Noels L, Jaffee MS, Radovitzky RA. Computational biology - modeling of primary blast effects on the central nervous system. Neuroimage. 2009;47 Suppl 2:T10-20.

[28] Chafi M, Karami G, Ziejewski M. Biomechanical assessment of brain dynamic responses due to blast pressure waves. Annals of Biomedical Engineering. 2010;38:490-504. [29] Ganpule S, Alai A, Plougonven E, Chandra N. Mechanics of blast loading on the head models in the study of traumatic brain injury using experimental and computational approaches. Biomechanics \& Modeling in Mechanobiology. 2012;12:511-31.

[30] Nahum AM, Smith R, Ward CC. Intracranial pressure dynamics during head impact. 21st Stapp Car Crash Conference. San Diego, USA: Society of Automotive Engineers (SAE), SAE Paper No. 770922; 1977. p. 339-66.

[31] Lee HP, Gong SW. Finite element analysis for the evaluation of protective functions of helmets against ballistic impact. Computer Methods in Biomechanics and Biomedical Engineering. 2010;13:537-50. 
[32] IWEAPONS® Protective Face Visor Shield Bulletproof Helmet Armor NIJ IIIA Green.

[33] Zhang L, Sharma S. Computational modeling of causal mechanisms of blast wave induced traumatic brain injury - a potential tool for injury prevention. Wayne State University, Annual report prepared for U.S. Army Medical Research and Material Command; 2009.

[34] Grujicic A, LaBerge M, Grujicic M, Pandurangan B, Runt J, Tarter J, et al. Potential improvements in shock-mitigation efficacy of a polyurea-augmented advanced combat helmet. J of Materi Eng and Perform. 2012;21:1562-79.

[35] Vechart A. Design of a Composite Combat Helmet Liner for Prevention of BlastInduced Traumatic Brain Injury: Massachusetts Institute of Technology; 2011.

[36] What is Aerogel? 2013.

[37] Polycarbonate Technical Data and Information. 2013.

[38] Corwin F. Characterization of a blast wave device and blast wave induced traumatic brain injury in a rat model by magnetic resonance imaging and spectroscopy: Virginia Commonwealth University; 2011.

[39] National Academies and the Department of Homeland Security. IED Attack Improvised Explosive Devices. Retrieved from:

http://www.dhs.gov/xlibrary/assets/prep_ied_fact_sheet.pdf. (Accessed on 25th June 2015).

[40] Global Security Organization. Explosives. Retrieved from:

http://www.globalsecurity.org/military/systems/munitions/explosives.htm. (Accessed on 25th June 2015).

[41] Hyde D. ConWep: Conventional weapons effects program. ERDC Vicksburg MS; 1991.

[42] Gibson PW. Blast overpressure and survivability calculations for various sizes of explosive charges. 1994. p. 24.

[43] Simmonds KE, Bagchi A, Leung AC, III WRP, Matic P, Byers JM, et al. Sensor systems for measuring helmet-head-brain response to blast. Washington, DC: Division of Material Science And Technology, Naval Research Lab (NRL); 2009. p. 1-12.

[44] Stewart C. Blast injuries: Preparing for the inevitable. Emergency Medicine Practice. 2006;8:1-28.

[45] Richmond DR, Damon EG, Fletcher ER, Bowen IG, White CS. The relationship between selected blast-wave parameters and the response of mammals exposed to air blast*. Annals of the New York Academy of Sciences. 1968;152:103-21.

[46] Grujicic M, Bell WC, Pandurangan B, He T. Blast-wave impact-mitigation capability of polyurea when used as helmet suspension-pad material. Materials \& Design. 2010;31:405065.

[47] Grujicic M, Arakere A, Pandurangan B, Grujicic A, Littlestone AA, Barsoum RS. Computational investigation of shock-mitigation efficacy of polyurea when used in a combat helmet: a core sample analysis. Multidiscipline Modeling in Materials and Structures. 2012;8:297-331.

[48] Ward CC, Chan M, Nahum AM. Intracranial pressure-a brain injury criterion. 24th Stapp Car Crash Conference. Warrendale, USA: Society of Automotive Engineers (SAE), SAE Paper No. 801304.; 1980. p. 347-60. 
[49] Taylor PA, Ford CC. Simulation of blast-induced early-time intracranial wave physics leading to traumatic brain injury. Journal of Biomechanical Engineering. 2009;131.

[50] Wood JL. Dynamic response of human cranial bone. Journal of Biomechanics. 1971;4:12, IN1-IN3, -12.

[51] Prospector. Polycarbonate (PC) Typical Properties Generic ABS+PC. 2015. Retrieved from: http://plastics.ulprospector.com/generics/25/c/t/polycarbonate-pc-propertiesprocessing. (Accessed on 25th June 2015).

[52] Woignier T, Primera J, Alaoui A, Etienne P, Despestis F, Calas-Etienne S. Mechanical Properties and Brittle Behavior of Silica Aerogels. Gels. 2015;1:256.

[53] Parmenter KE, Milstein F. Mechanical properties of silica aerogels. Journal of NonCrystalline Solids. 1998;223:179-89.

[54] Petr K, Bondi MW, Ward SR, Frank LR. On sources of error in finite element simulations of blast effects in the human brain. Journal of Computational and Nonlinear Dynamics. 2012;7:031008-.

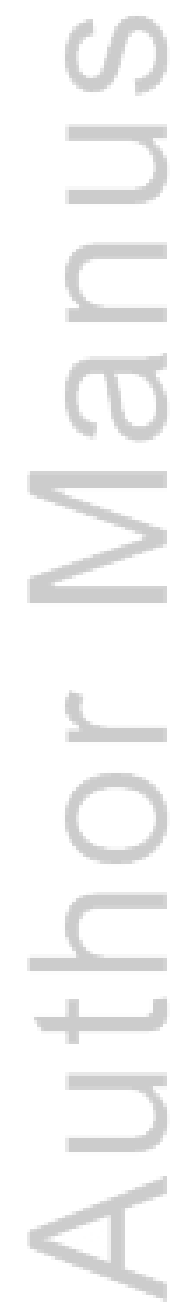

This article is protected by copyright. All rights reserved. 
Table 1: Details of each of the simulation cases.

Case No. Type of Cases

\begin{tabular}{cl}
\hline \hline 1 & Helmet without face shield \\
\hline 2 & Helmet with 3mm polycarbonate (PC) face shield \\
\hline 3 & Helmet with sandwiched PC/aerogel/PC face shield (same geometry as \#1) \\
\hline 4 & $\begin{array}{l}\text { Helmet with sandwiched PC/aerogel/PC face shield and extended 45mm lateral } \\
\text { edge }\end{array}$ \\
\hline \hline
\end{tabular}

4
0
0
$\square$
$\square$
$\square$

This article is protected by copyright. All rights reserved. 
Table 2: Material properties of the FE models of human head, face shield, PASGT helmet as well as the ambient air.

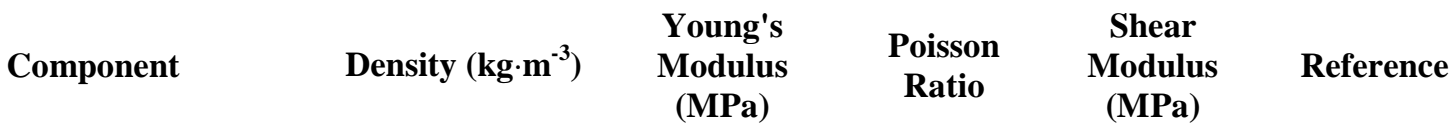

\begin{tabular}{|c|c|c|c|c|c|}
\hline Human Head Assembly & & & & & \\
\hline CSF & 1040 & 0.15 & 0.499 & - & {$[7,31]$} \\
\hline Dura & 1140 & 31.5 & 0.45 & - & {$[7,31]$} \\
\hline Face & 2500 & 5540 & 0.22 & - & {$[7,31]$} \\
\hline Flax & 1140 & 31.5 & 0.45 & - & {$[7,31]$} \\
\hline Cerebellum & 1040 & 0.123 & 0.49 & - & {$[7,31]$} \\
\hline Cerebrum & 1040 & 2.19 & 0.499 & - & {$[7,31]$} \\
\hline Neck & 1060 & 110 & 0.45 & - & [7] \\
\hline Pia & 1130 & 11.5 & 0.45 & - & {$[7,31]$} \\
\hline Tentorium & 1140 & 31.5 & 0.45 & - & {$[7,31]$} \\
\hline Scalp & 1130 & 16.7 & 0.42 & - & {$[7,31]$} \\
\hline Skull Cortical Bone & 2000 & 15000 & 0.22 & - & {$[7,31]$} \\
\hline Skull (Trabecular Bone) & 1300 & 1000 & 0.24 & - & {$[7,31]$} \\
\hline \multicolumn{6}{|l|}{ Helmet Assembly } \\
\hline Backrest (Polyurethane) & 160 & 57 & 0.24 & - & {$[7,31]$} \\
\hline Inner Strap (Leather) & 1153 & 500 & 0.3 & - & {$[7,31]$} \\
\hline PASGT Helmet Shell & 1230 & $\begin{array}{c}\mathrm{E}_{11}^{\#}=20000 \\
\mathrm{E}_{22}=20000 \\
\mathrm{E}_{33}=7000\end{array}$ & $\begin{array}{l}v_{13}=0.33 \\
v_{23}=0.33 \\
v_{12}=0.77\end{array}$ & $\begin{array}{l}\mathrm{G}_{12}=7700 \\
\mathrm{G}_{13}=2715 \\
\mathrm{G}_{23}=2715\end{array}$ & {$[7,31]$} \\
\hline Strap (Nylon Polyester) & 1160 & 2400 & 0.35 & - & {$[7,31]$} \\
\hline Strip (Nylon Polyester) & 1160 & 2400 & 0.35 & - & {$[7,31]$} \\
\hline \multicolumn{6}{|l|}{ Face shield Assembly } \\
\hline Bracket (Aluminium) & 2700 & 70000 & 0.35 & - & [35] \\
\hline Visor (Aerogel Layer) & 100 & 10 & 0.2 & - & {$[36]$} \\
\hline Visor (Polycarbonate Layer) & 1220 & 2400 & 0.37 & - & [37] \\
\hline \multirow{4}{*}{ Air } & Density $\left(\mathbf{k g} \cdot \mathbf{m}^{-3}\right)$ & $\begin{array}{c}\text { Dynamic } \\
\text { Viscousity } \\
\left(\mathrm{kg} \cdot \mathrm{m}^{-1} \cdot \mathrm{s}^{-1}\right)\end{array}$ & $\begin{array}{c}\text { Specific } \\
\text { Heat @ } \\
\text { Constant } \\
\text { Pressure } \\
\left(\mathbf{J} \cdot \mathbf{k g}^{-1} \cdot \mathbf{K}^{-1}\right) \\
\end{array}$ & $\begin{array}{l}\text { Ambient } \\
\text { Pressure } \\
\text { (MPa) }\end{array}$ & \\
\hline & 1.18 & $1.8 \mathrm{E}-5$ & 1005 & 0.10365 & [7] \\
\hline & $\begin{array}{c}\text { Initial Ambient } \\
\text { Temperature } \\
\left({ }^{\circ} \mathrm{C}\right)\end{array}$ & $\begin{array}{l}\text { Absolute } \\
\text { Zero }\left({ }^{\circ} \mathrm{C}\right)\end{array}$ & $\begin{array}{c}\text { Gas } \\
\text { Constant } \\
\left(\mathbf{J} \cdot \mathbf{k g}^{-1} \cdot \mathbf{K}^{-1}\right) \\
\end{array}$ & & \\
\hline & 30.0 & -273.0 & 287.04 & & [7] \\
\hline
\end{tabular}

\footnotetext{
\# 1 and 2 are in-plane directions of the helmet, while 3 denotes the through-thickness direction for the helmet.
} 


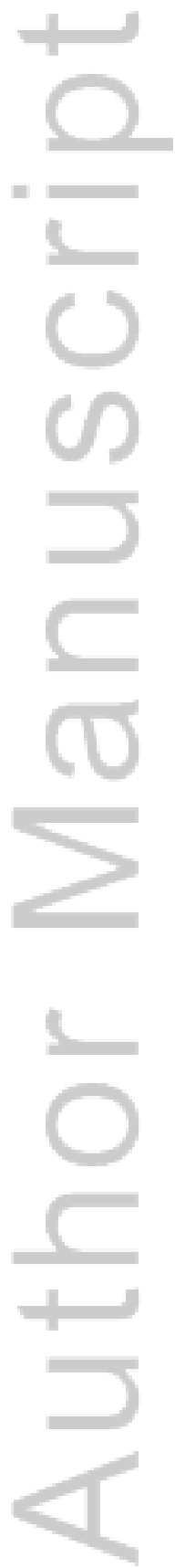

This article is protected by copyright. All rights reserved. 
Table 3: Peak ICPs at the frontal and parietal lobes for cases with and without face shield.

\begin{tabular}{|c|l|l|l|l|}
\hline Locations & Case No. & $\begin{array}{c}\text { Peak Positive } \\
\text { Pressure (kPa) }\end{array}$ & $\begin{array}{l}\text { Peak Negative } \\
\text { Pressure (kPa) }\end{array}$ & $\begin{array}{c}\text { Pressure @ } \\
\text { Initial Peak } \\
\text { With No Face } \\
\text { Shield (kPa) }\end{array}$ \\
\hline Frontal Lobe & $\begin{array}{c}\text { Case 1 (No Face } \\
\text { Shield) }\end{array}$ & 154 & -130 & 130 \\
\cline { 2 - 6 } & $\begin{array}{c}\text { Case 2 (PC Face } \\
\text { Shield) }\end{array}$ & 178.5 & -87 & -49 \\
\hline Parietal Lobe & $\begin{array}{c}\text { Case 1 (No Face } \\
\text { Shield) }\end{array}$ & 173 & -119 & 104 \\
\cline { 2 - 6 } & $\begin{array}{c}\text { Case 2 (PC Face } \\
\text { Shield) }\end{array}$ & 134 & -112 & -20 \\
\hline
\end{tabular}

This article is protected by copyright. All rights reserved. 
Table 4: Comparison of skull stress and ICPs between PC and PC/aerogel composite face shields.

\begin{tabular}{|c|c|l|l|l|}
\hline Locations & Case No. & $\begin{array}{c}\text { Max. Skull } \\
\text { Mises Stress } \\
(\mathbf{M P a})\end{array}$ & Max. ICP (kPa) & Min. ICP (kPa) \\
\hline \multirow{2}{*}{ Frontal } & Case 3 (PC) & 5.49 & 178.5 & -87.0 \\
\cline { 2 - 5 } & $\begin{array}{c}\text { Case 4 } \\
(\text { PC/Aerogel/PC) }\end{array}$ & 5.35 & 183.6 & -140.0 \\
\hline Parietal & Case 3 (PC) & 3.47 & 134.0 & -112.0 \\
\cline { 2 - 5 } & $\begin{array}{c}\text { Case 4 } \\
(\text { PC/Aerogel/PC) }\end{array}$ & 3.73 & 128.7 & -90.5 \\
\hline Occipital & Case 3 (PC) & 3.50 & 221.4 & -177.1 \\
\cline { 2 - 5 } & $\begin{array}{c}\text { Case 4 } \\
\text { Temporal }\end{array}$ & 4.60 & 173.6 & -123.3 \\
\cline { 2 - 5 } & Case 3 (PC) & 4.90 & 233.8 & -195.2 \\
\hline & $\begin{array}{c}\text { Case 4 } \\
\text { (PC/Aerogel/PC) }\end{array}$ & 7.70 & 215.2 & -174.3 \\
\hline
\end{tabular}

This article is protected by copyright. All rights reserved. 

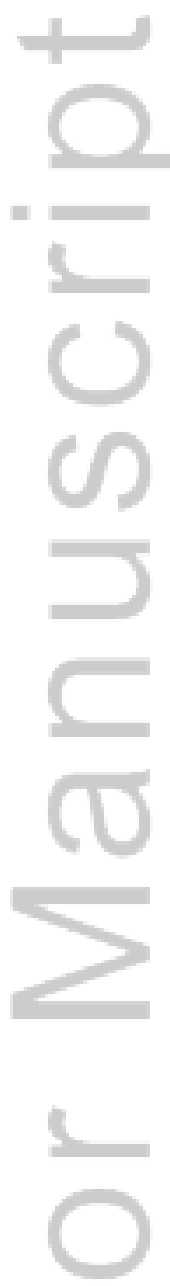

妾
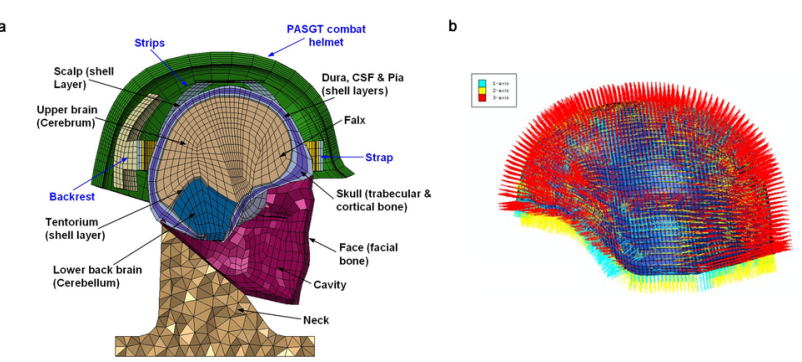

CNM_2884_F1.tif

This article is protected by copyright. All rights reserved. 

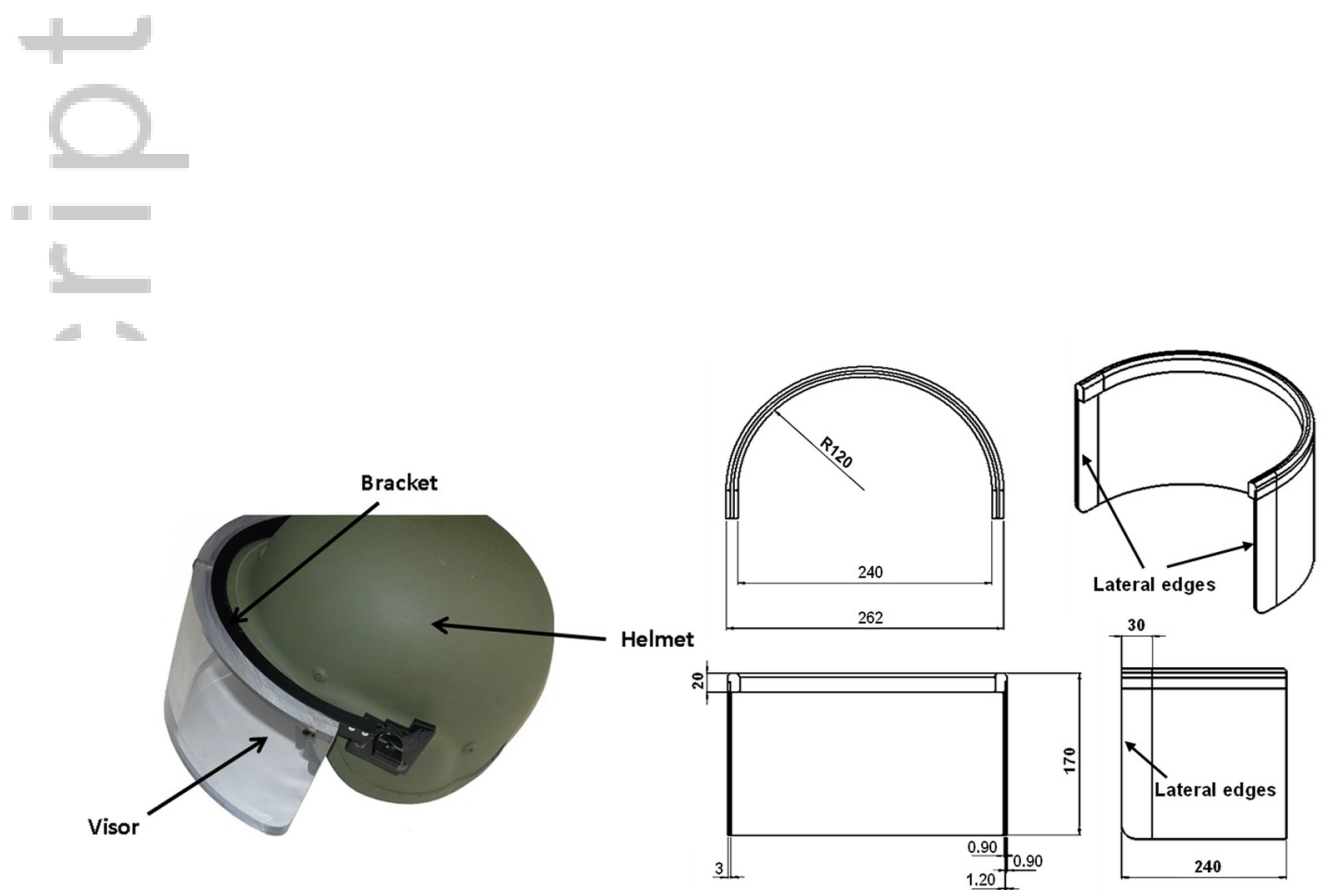

30

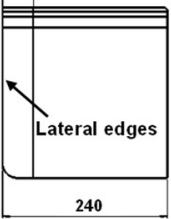

b

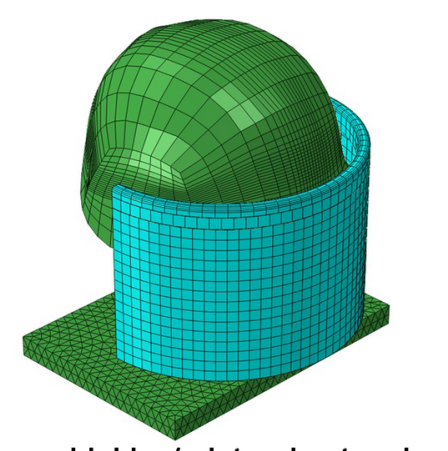

Face shield w/o lateral extension

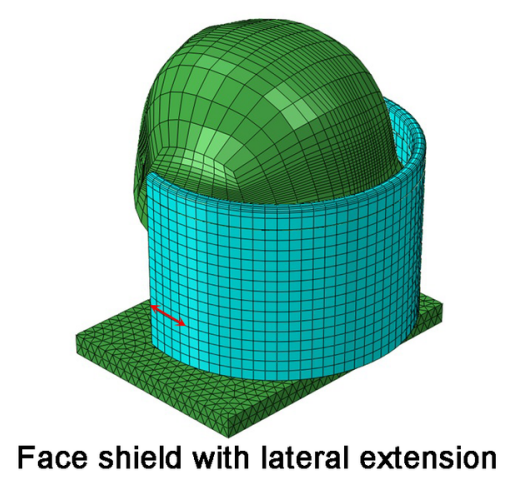

CNM_2884_F2.tif

This article is protected by copyright. All rights reserved. 


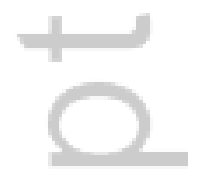

a

Blue Surface: Non-reflecting and free inflow boundary condition

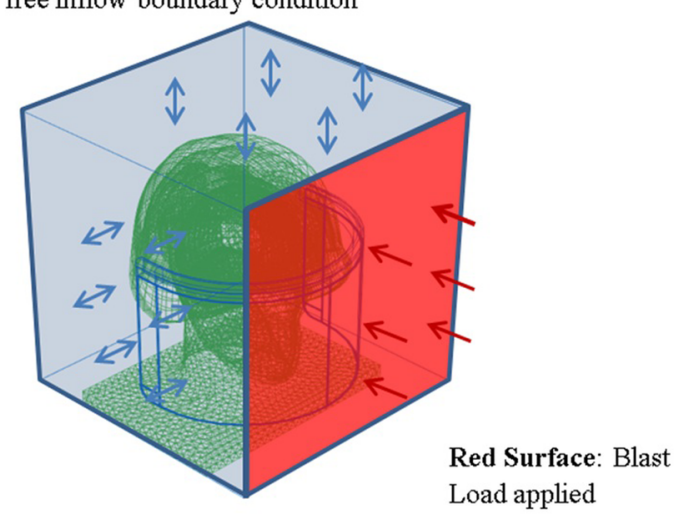

b

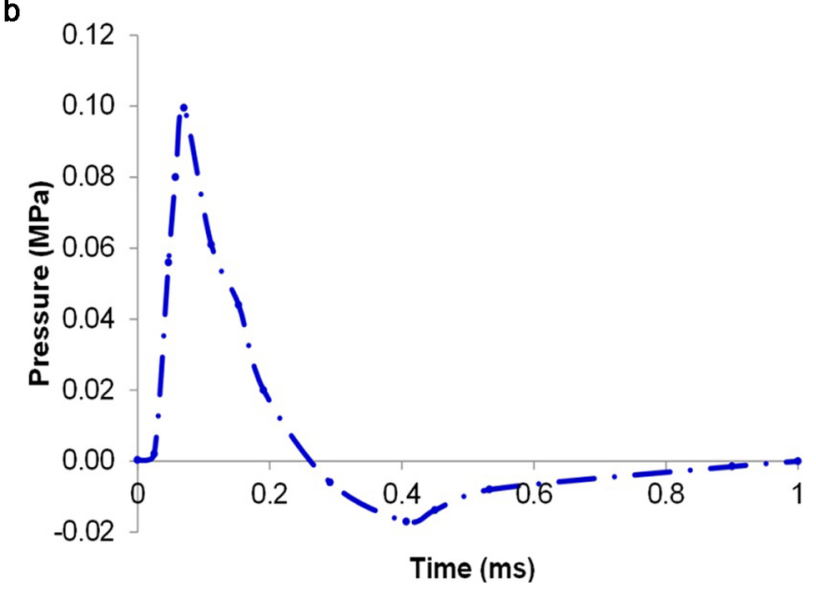

CNM_2884_F3.tif

This article is protected by copyright. All rights reserved. 


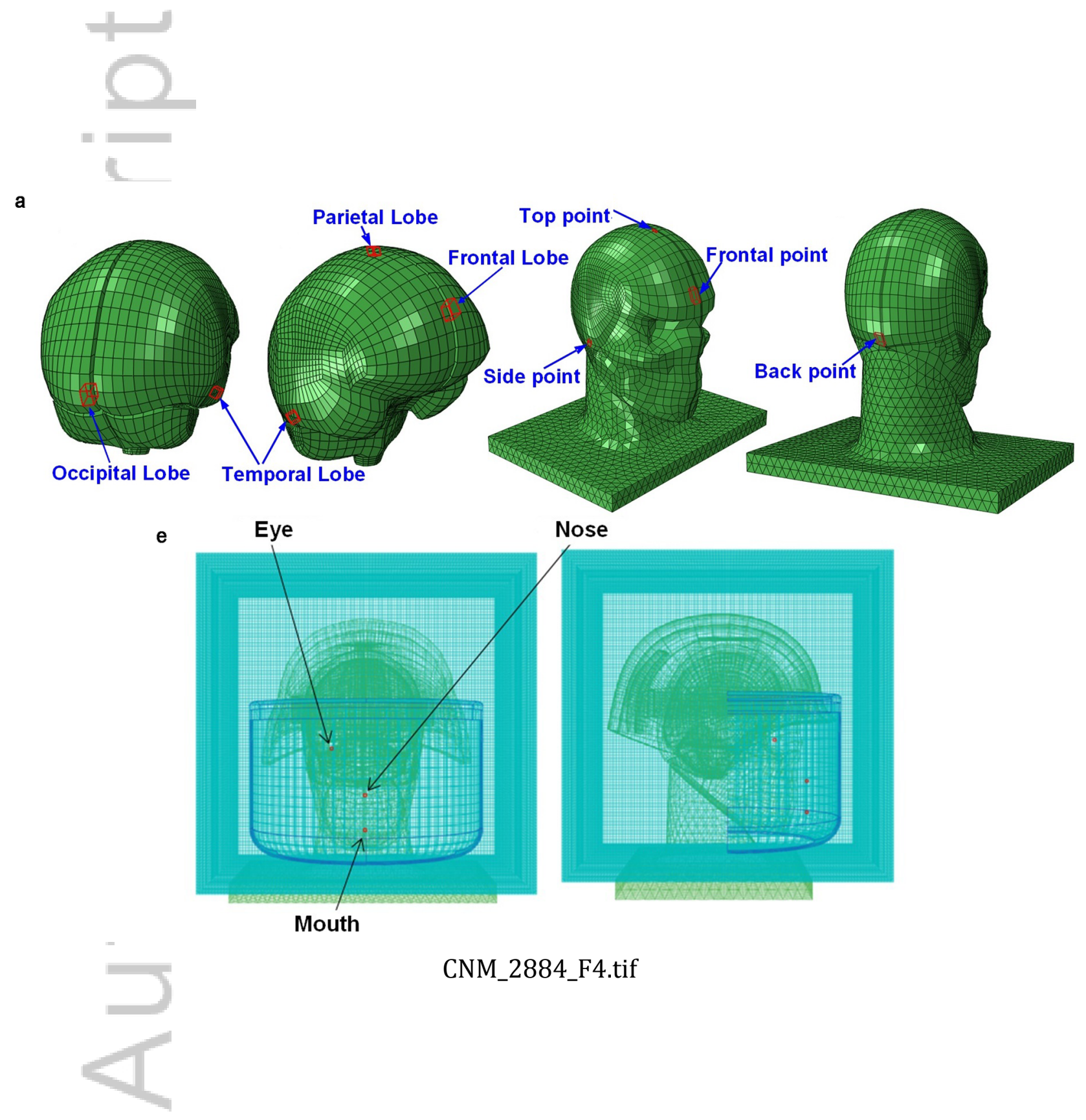

This article is protected by copyright. All rights reserved. 


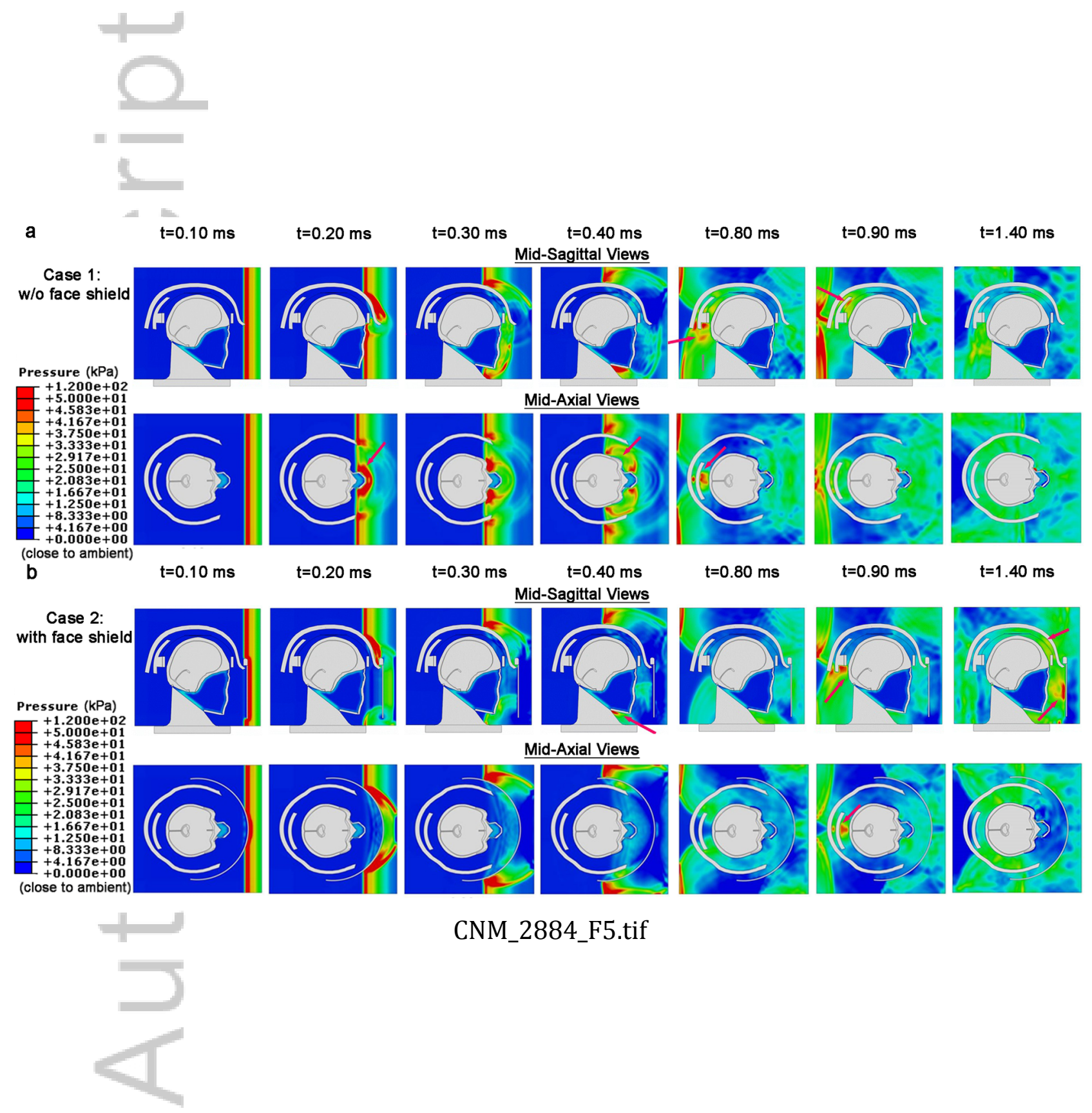

This article is protected by copyright. All rights reserved. 


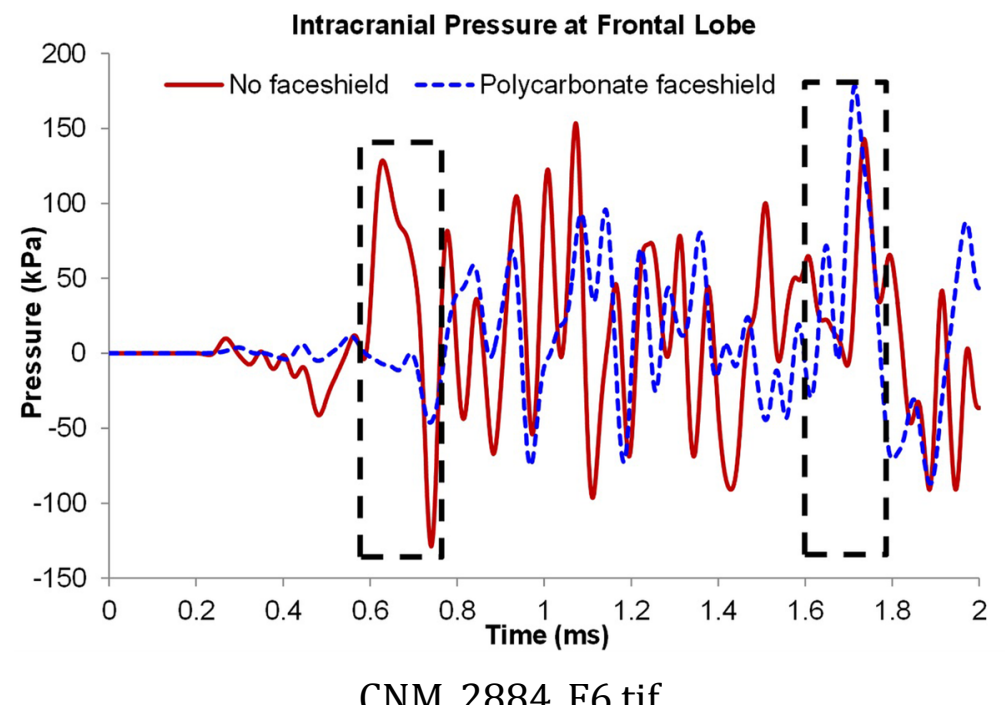

CNM_2884_F6.tif

This article is protected by copyright. All rights reserved. 

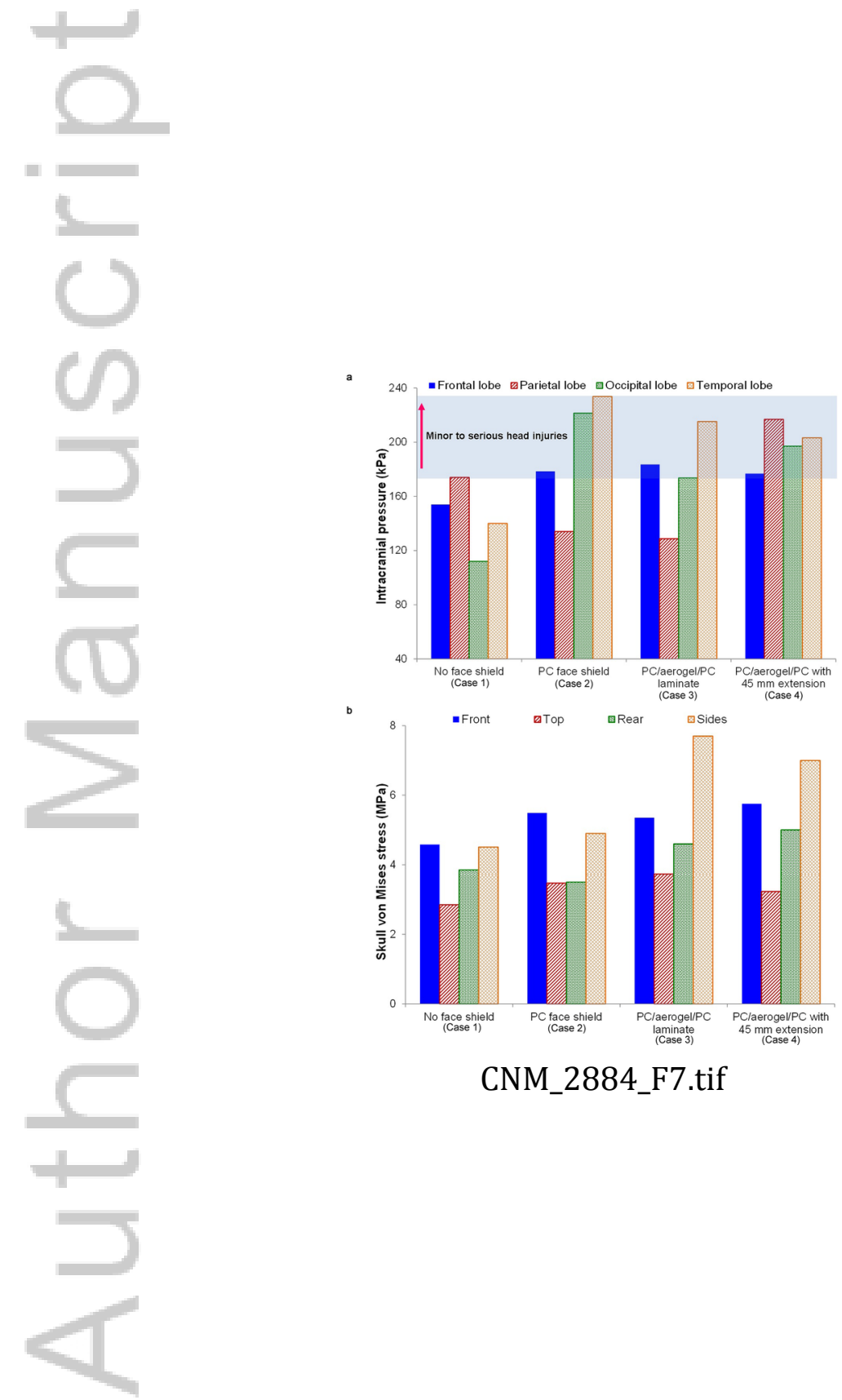

CNM_2884_F7.tif

This article is protected by copyright. All rights reserved. 

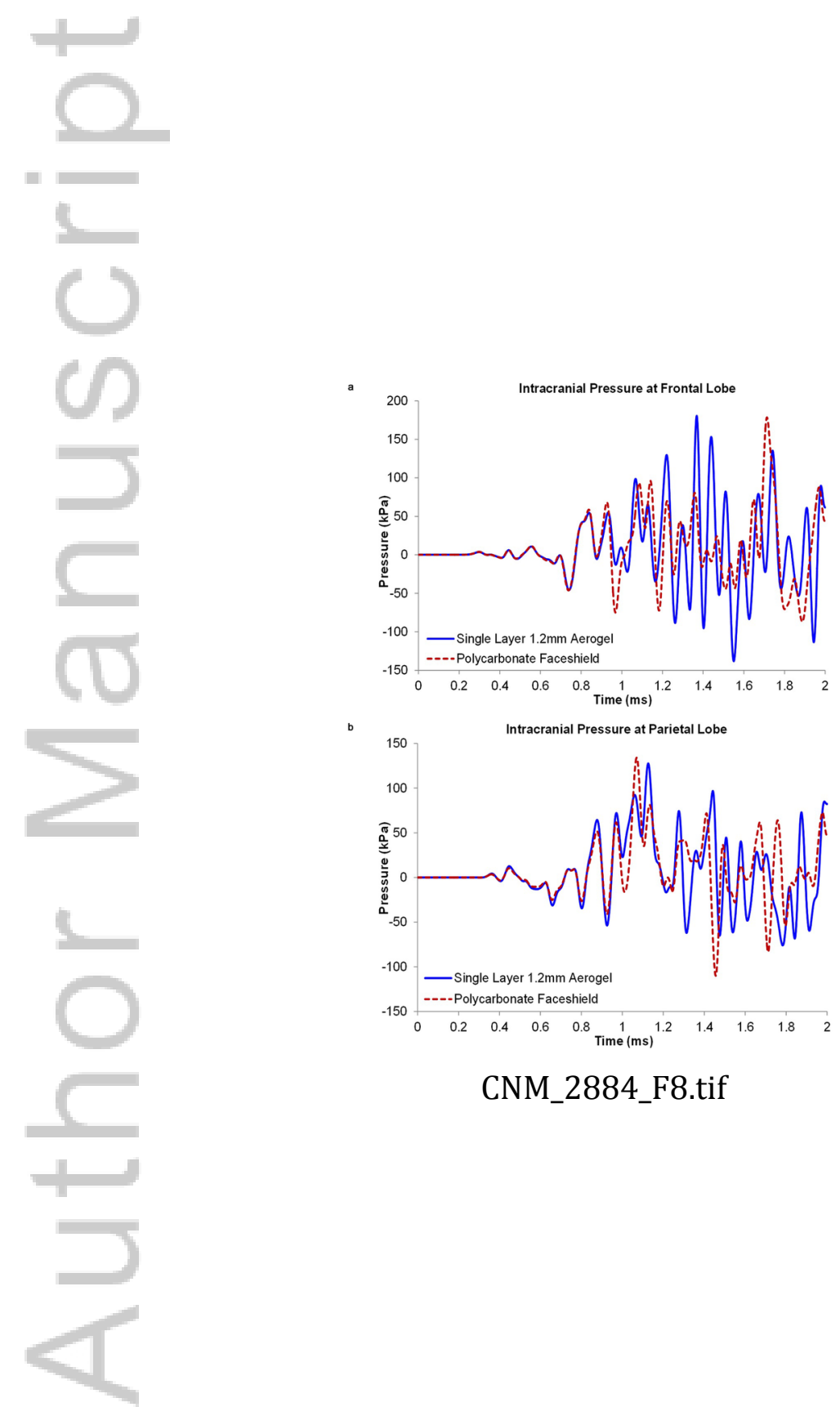

CNM_2884_F8.tif

This article is protected by copyright. All rights reserved. 
Case 3:

with laminated $\mathrm{PC} /$ aerogel/PC face shield

Case 4: with laminated PC/aerogel/PC face shield, with latera extension

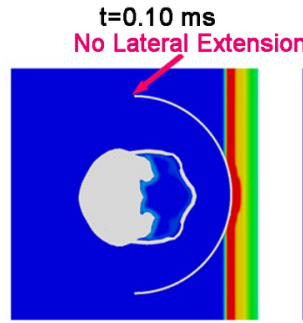

$\mathrm{t}=0.65 \mathrm{~ms}$

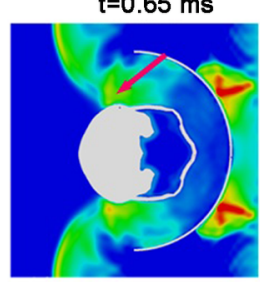

$\mathrm{t}=0.10 \mathrm{~ms}$ With Lateral Extension

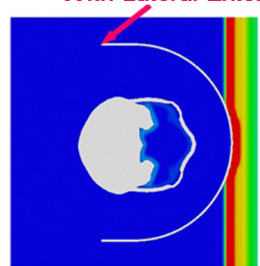

$\mathrm{t}=0.65 \mathrm{~ms}$
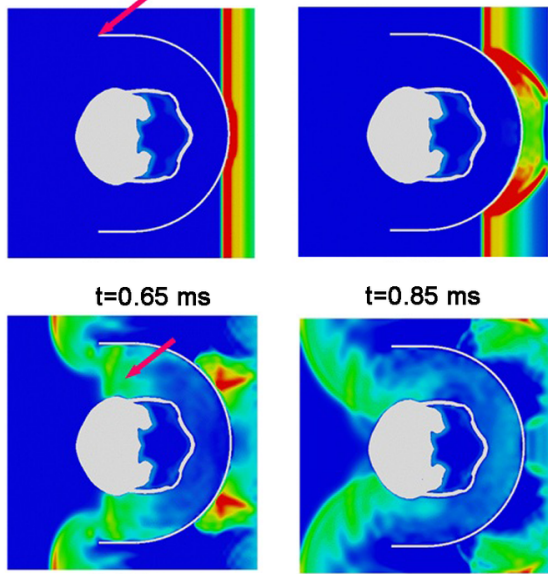

$\mathrm{t}=0.85 \mathrm{~ms}$

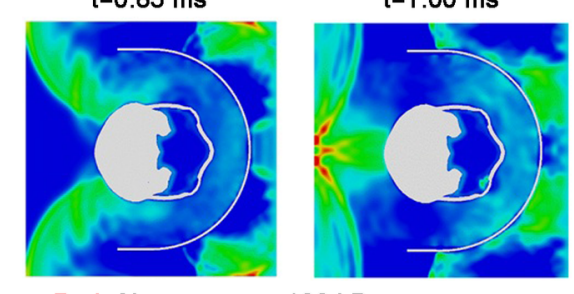

Red: Air pressure $>100 \mathrm{kPa}$

Blue: Air pressure close to ambient

CNM_2884_F9.tif

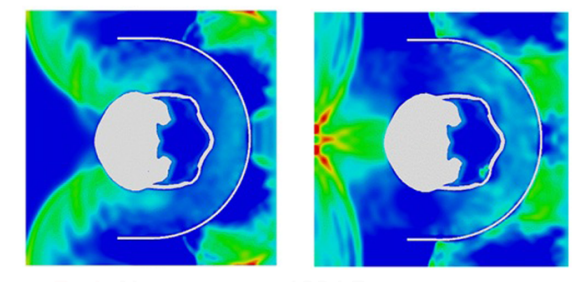

$\mathrm{t}=0.30 \mathrm{~ms}$

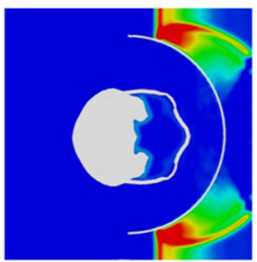

$\mathrm{t}=1.00 \mathrm{~ms}$

$\mathrm{t}=0.30 \mathrm{~ms}$

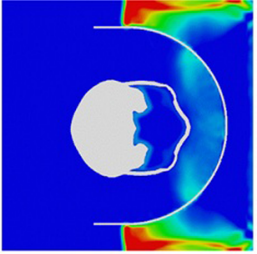

$\mathrm{t}=1.00 \mathrm{~ms}$

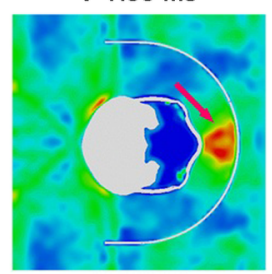

$\mathrm{t}=1.90 \mathrm{~ms}$

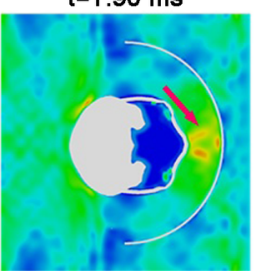

$\mathrm{t}=0.40 \mathrm{~ms}$

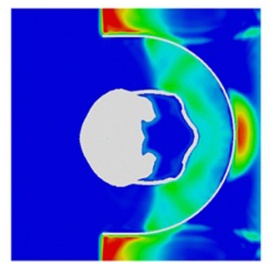

$\mathrm{t}=1.90 \mathrm{~ms}$

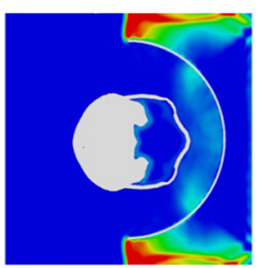

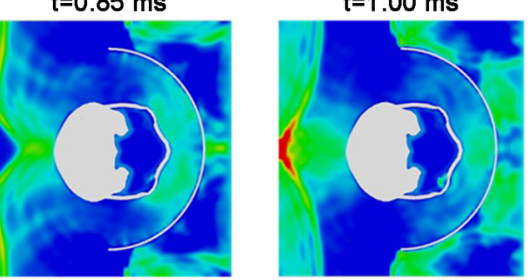

.

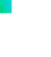



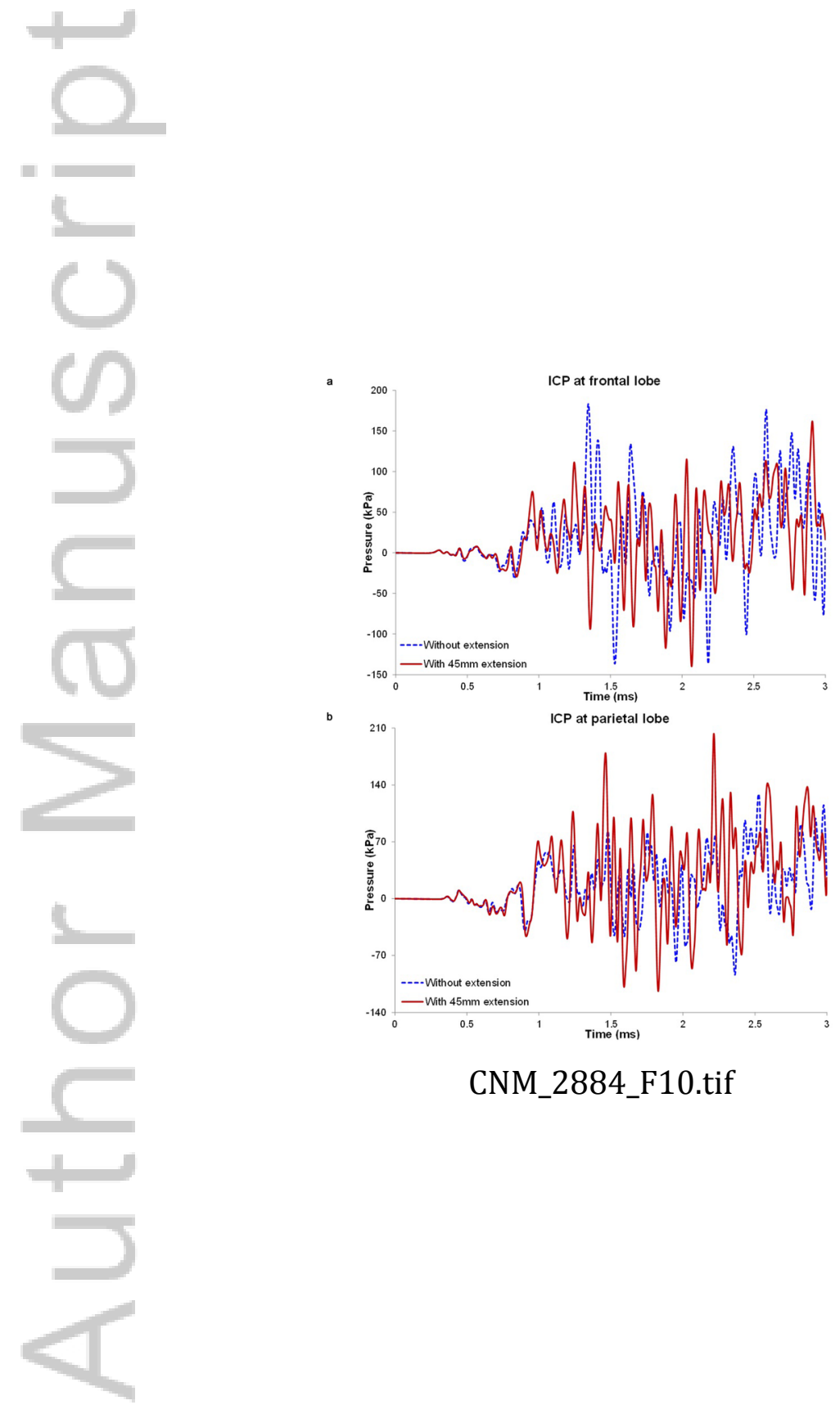

This article is protected by copyright. All rights reserved. 

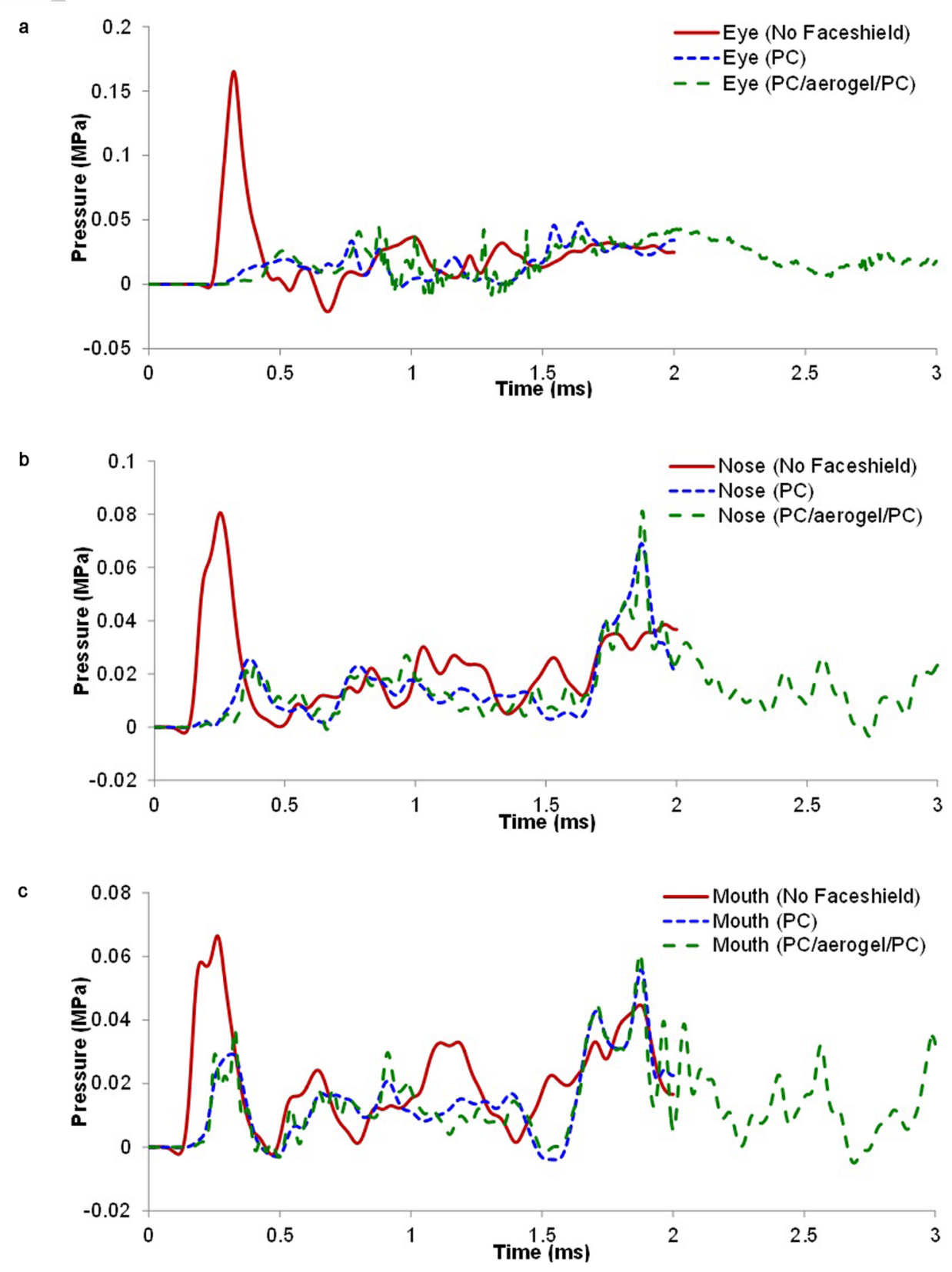

CNM_2884_F11.tif

This article is protected by copyright. All rights reserved. 


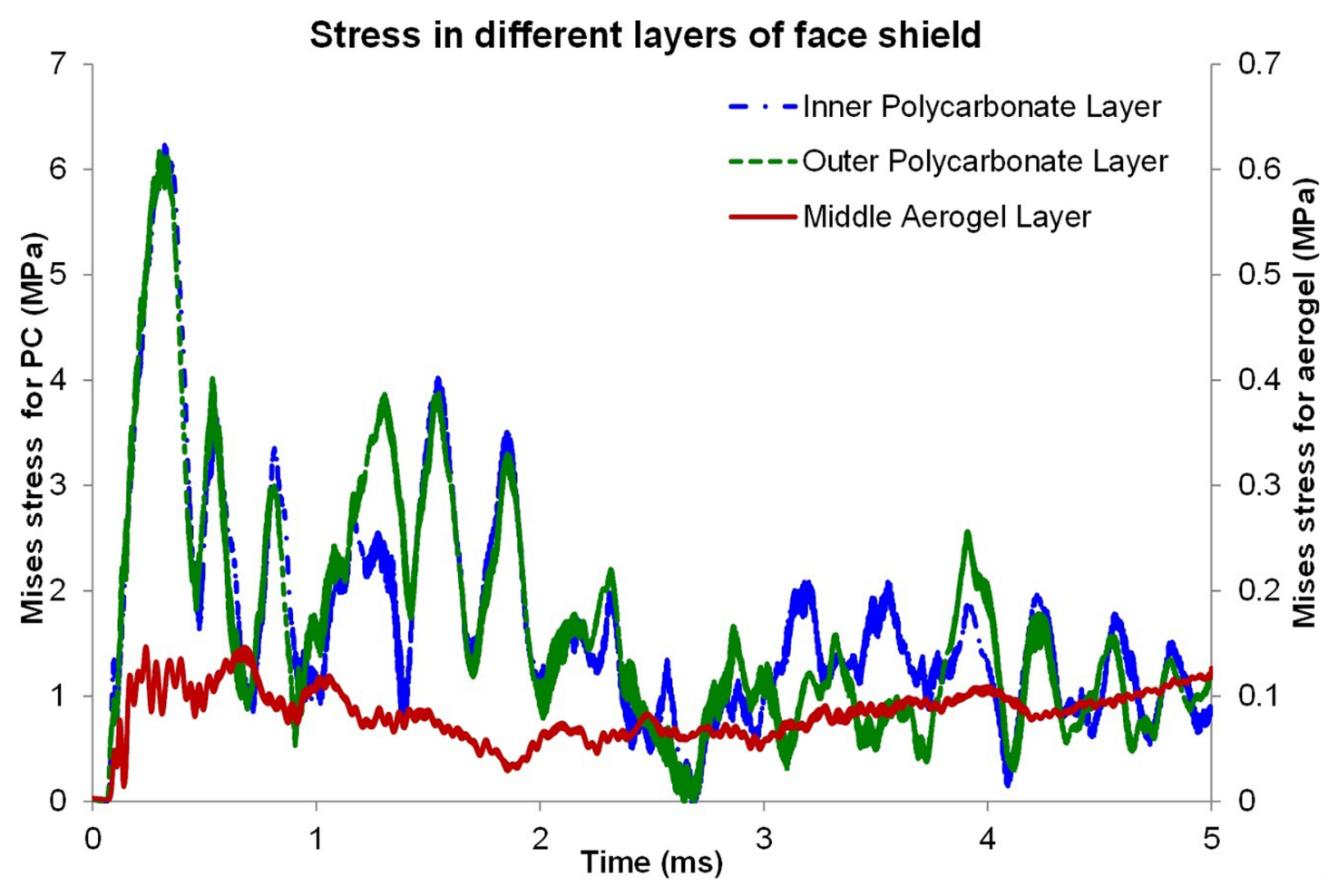

CNM_2884_F12.tif

This article is protected by copyright. All rights reserved. 


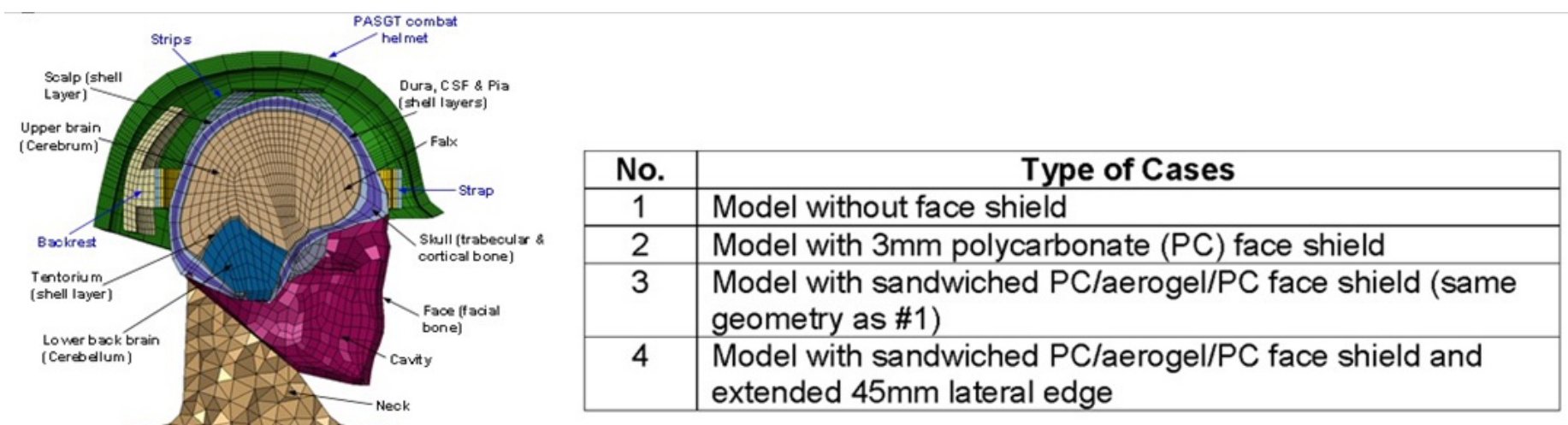

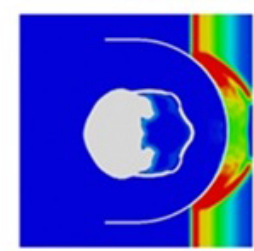

$0.20 \mathrm{~ms}$

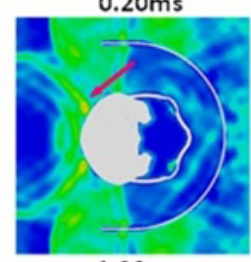

$1.30 \mathrm{~ms}$

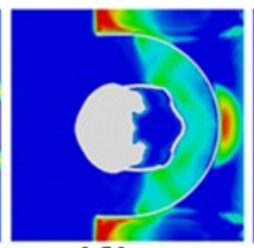

$0.50 \mathrm{~ms}$

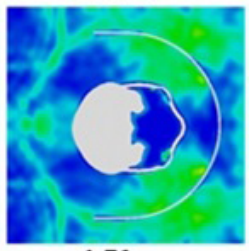

$1.70 \mathrm{~ms}$

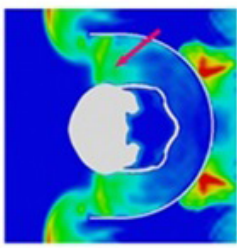

$0.65 \mathrm{~ms}$

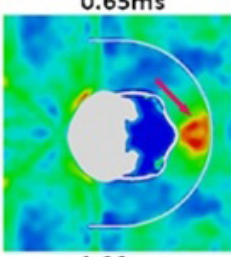

$1.90 \mathrm{~ms}$

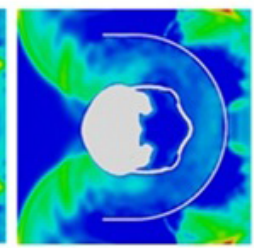

$0.80 \mathrm{~ms}$

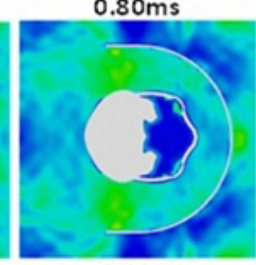

$2.30 \mathrm{~ms}$

With extended face shield edges - high pressure air accumulation \& retention at facial regions at later time

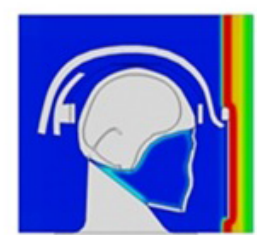

$0.10 \mathrm{~ms}$

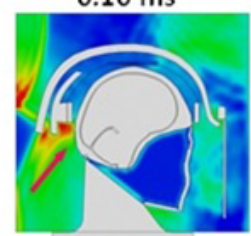

$0.90 \mathrm{~ms}$

$1.15 \mathrm{~ms}$

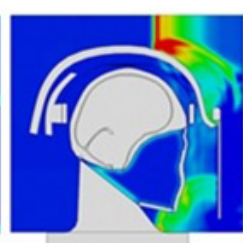

$0.30 \mathrm{~ms}$
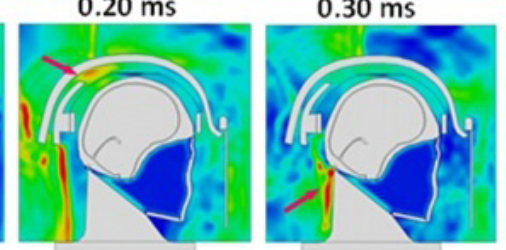

$1.25 \mathrm{~ms}$

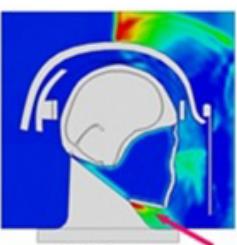

$0.40 \mathrm{~ms}$

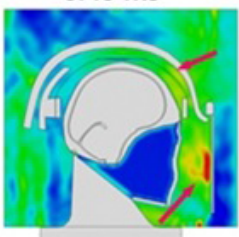

$1.40 \mathrm{~ms}$

With PC face shield - diffracted wave from shield edges

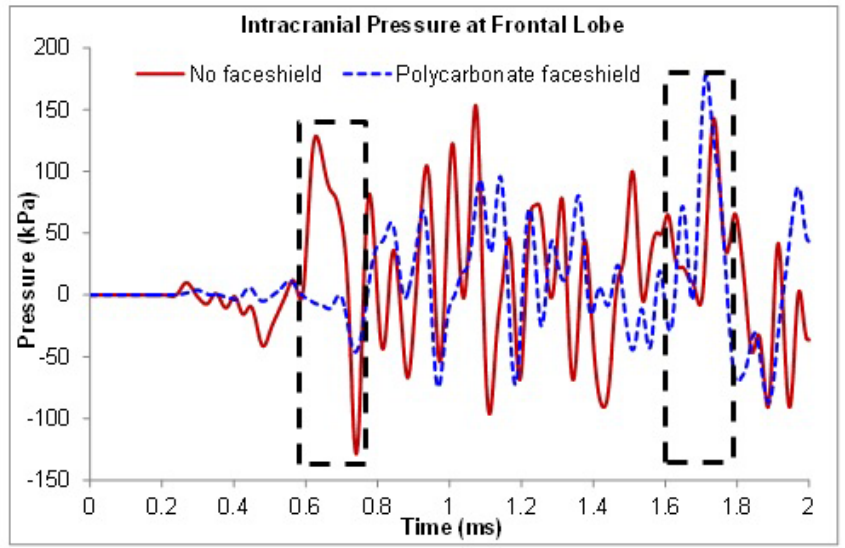

Pressure-time profile of frontal lobe during blast sequence
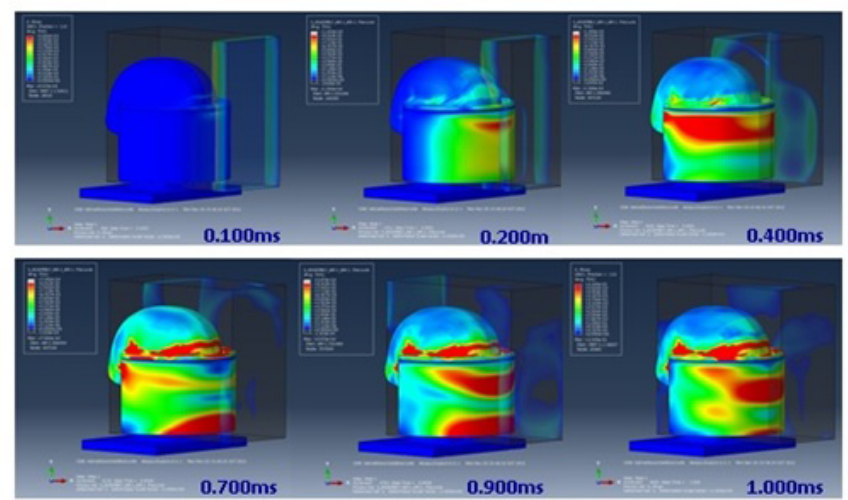

Analysis of blast mitigation performance of PC/aerogel/PC composite face shield

CNM_2884_GTOC.tif 